
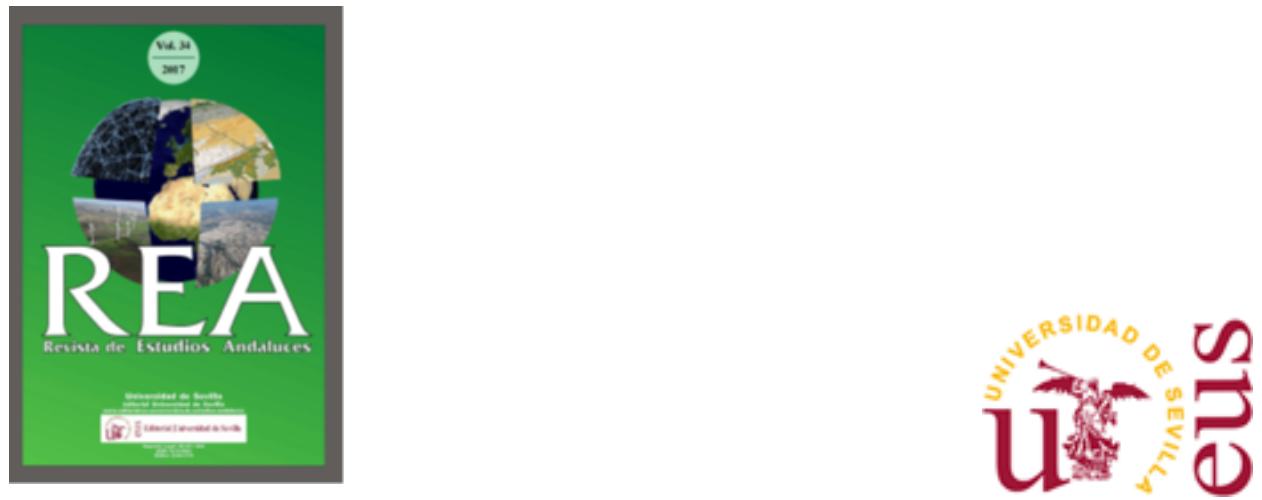

\title{
Revista de Estudios Andaluces (REA)
}

e-ISSN: $2340-2776$.

REA Vol. 34 (2017). http://dx.doi.org/10.12795/rea.2017.i34

\section{Análisis Integral de los Usos del Territorio para el Desarrollo de Zonas Degradadas por la Minería: El Entorno de Portmán (La Unión)}

\section{Comprehensive Analysis of Territorial Uses for the Development of Mining Degraded Areas: The Surrounding of Portmán (La Unión)}

\author{
Patricia Esteve-Guirao \\ Universidad de Murcia \\ p.esteve@um.es \\ Isabel Banos-González \\ Universidad de Murcia \\ ibbg1@um.es \\ Pedro Baños-Páez \\ Universidad de Murcia \\ pbanos@um.es \\ Pedro Pérez-Cutillas \\ Universidad de Murcia \\ pedrope@um.es
}

\section{Emilio Díez de Revenga-Martínez Ambiental S.L.} emilio.diezderevenga@ambiental-sl.es Magdalena Martínez-Pedrero Ambiental S.L. magdalena.martinez@ambiental-sl.es María Lluna-Diaz Ambiental S.L. Iluna.diaz@ambiental-sl.es

Formato de cita / Citation: Esteve-Guirao, Patricia; Banos-González, Isabel; Baños-Páez, Pedro; Pérez-Cutillas, Pedro; Díez de Revenga-Martínez, Emilio; Martínez-Pedrero, Magdalena; Lluna-Díaz, María (2017). Análisis Integral de los Usos del Territorio para el Desarrollo de Zonas Degradadas por la Minería: El Entorno de Portmán (La Unión). Revista de Estudios Andaluces, vol. 34 (1), 89-119. http://dx.doi.org/10.12795/rea.2017.i34.04

Enlace artículo / to link to this article: http://dx.doi.org/10.12795/rea.2017.i34.04

\footnotetext{
Esta obra se distribuye con la licencia Creative Commons Reconocimiento-NoComercialSinObraDerivada 4.0 Internacional
}

(c) (7) $\ominus$ 


\title{
Análisis Integral de los Usos del Territorio para el Desarrollo de Zonas Degradadas por la Minería: El Entorno de Portmán (La Unión) \\ Comprehensive Analysis of Territorial Uses for the Development of Mining Degraded Areas: The Surrounding of Portmán (La Unión)
}

\author{
Patricia Esteve-Guirao \\ Universidad de Murcia \\ p.esteve@um.es \\ Isabel Banos-González \\ Universidad de Murcia \\ ibbg1@um.es \\ Pedro Baños-Páez \\ Universidad de Murcia \\ pbanos@um.es \\ Pedro Pérez-Cutillas \\ Universidad de Murcia \\ pedrope@um.es \\ Emilio Díez de Revenga-Martínez \\ Ambiental S.L. \\ emilio.diezderevenga@ambiental-sl.es \\ Magdalena Martínez-Pedrero \\ Ambiental S.L. \\ magdalena.martinez@ambiental-sl.es \\ María Lluna-Diaz \\ Ambiental S.L. \\ Iluna.diaz@ambiental-sl.es
}

Recibido: 20 de enero, 2017

Revisado: 03 de abril, 2017

Aceptado: 05 de abril, 2017

Resumen

La bahía de Portmán, SE de la Península Ibérica, alberga el escenario de uno de los mayores desastres ambientales del litoral mediterráneo: la colmatación de la bahía provocada por el vertido de toneladas de estériles de minería al mar durante más de treinta años. El análisis de los valores del entorno y el estudio del potencial de desarrollo de la bahía se plantea con el objetivo de obtener alternativas de planificación de un desarrollo local sostenible y respetuoso con el entorno. Se han realizado dos fases de análisis: la primera a través de un estudio sectorial, más pormenorizado; la segunda fase de análisis, con una evaluación global de los usos del suelo para determinar los

Revista de Estudios Andaluces, vol. 34, núm. 1 (2017) pp. 89-119 e-ISSN: 2340-2776 http://dx.doi.org/10.12795/rea.2017.i34.04

(c) (i) $\ominus$

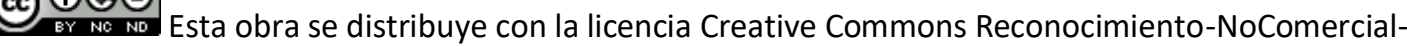
SinObraDerivada 4.0 Internacional 
condicionantes y las oportunidades de desarrollo del entorno de Portmán. El análisis integral llevado a cabo proporciona una visión del espacio en todo su conjunto, y permite definir categorías territoriales en relación a los posibles desarrollos en forma de proyectos residenciales y turísticos, que quedan definidas como: limitantes, condicionantes principales y condicionantes adicionales.

Palabras clave: Ordenación territorial, ecosistemas degradados, aptitudes del uso del suelo, minería.

\section{Abstract}

The Portmán Bay, Southeast Iberian Peninsula, is home to one of the largest environmental disasters on the Mediterranean coast: the silting of the bay caused by the dumping of million tonnes of mining waste to the sea, over more than thirty years. The analysis of the values of the surroundings, and the assessment of the potential for the development of the bay arises with the aim of obtaining alternatives for planning a sustainable local development and respectful with the environment. Two phases of analysis have been carried out: the first through a partial, more detailed, study; followed by a second phase of analysis, with an overall assessment of land uses to determine the constraints and development opportunities of the surroundings of Portmán. The integral analysis provides a vision of the space as a whole, and allows defining territorial categories in relation to possible developments in the form of residential and tourism projects, which are defined as: limitations, main constraints and additional constraints.

Keywords: Territorial planning, Degraded ecosystems, land use suitability, mining.

Revista de Estudios Andaluces, vol. 34, núm. 1 (2017) pp. 89-119. e-ISSN: 2340-2776 http://dx.doi.org/10.12795/rea.2017.i34.04

\section{c) (i) (3)}




\section{INTRODUCCIÓN}

Entre las localidades de Cartagena y Cabo de Palos (SE España), Portmán alberga hoy el escenario de uno de los mayores desastres ambientales del Mediterráneo: la colmatación de la bahía debido a los vertidos al mar de estériles, restos de lavado, de los minerales metálicos que durante más de treinta años realizó la empresa minera Peñarroya S.A.

En 1957, la Sociedad Minero-Metalúrgica Peñarroya comenzó las actividades extractivas de minerales a gran escala (Manteca y Ovejero, 1992). El lavadero para la concentración de mineral llegó a albergar una capacidad de procesamiento de $10.000 \mathrm{t} /$ día de mineral mediante un proceso de flotación que utilizaba agua de mar. Entre 1957 y 1990, los estériles eran vertidos directamente a la bahía con un caudal próximo a las $8.000 \mathrm{t} /$ día, ocupando el área entorno al vertido, en un radio de varios kilómetros (Benedicto et al., 2013). Cuando las actividades mineras cesaron, se estimó que casi 60 millones de toneladas de estériles habían sido vertidas en la bahía de Portmán, contribuyendo en un $50 \%$ a la entrada de metales pesados en el Mediterráneo y cerca del $90 \%$ de los aportes de residuos sólidos (Benedicto et al., 2008). Actualmente, más de un $80 \%$ de la bahía de Portmán se encuentra colmatada, afectando también a unas $10.000 \mathrm{Ha}$. de los fondos marinos de la plataforma continental. Casi 30 años después del cese de los vertidos, aún no hay garantías sobre un proyecto de recuperación para el entorno. El Proyecto de recuperación y adecuación ambiental de la Bahía de Portmán (BOE, 2011), promovido por el Ministerio de Medio Ambiente, licitado en septiembre de 2011, con DIA favorable y que contaba con el consenso de todas las administraciones implicadas y de los colectivos vecinales y ecologistas, quedó paralizado en 2013. Nuevas posibilidades de actuación y desarrollo del entorno de Portmán se están barajando en la actualidad, sin que exista certeza en la finalización de dichas actuaciones.

Desde una perspectiva socioeconómica, la regeneración de la bahía puede suponer un giro en los enfoques habituales de desarrollo local que han venido sufriendo las áreas costeras mediterráneas. Esta oportunidad debería presentar un modelo alternativo para la mejora del entorno, ya que, siguiendo los patrones convencionales de desarrollo, el turismo se puede utilizar como un instrumento para la construcción de nuevos espacios de crecimiento territorial (Benseny, 2006), pero las presiones ejercidas por un aumento de la población estacional en la costa, ponen en peligro la sustentabilidad ambiental del entorno (Espinosa y Rodríguez, 2015).

El cuidado de estos paisajes requiere un conocimiento de su morfología y procesos naturales, basado en la fragilidad y alta vulnerabilidad de sus ecosistemas, así como en una cuidadosa planificación y gestión sostenible (Vera Rebollo et al., 1997; López Bermúdez, 2013). La planificación territorial que pretende ordenar y estructurar un espacio geográfico debe basarse en un conocimiento pormenorizado del territorio que

Revista de Estudios Andaluces, vol. 34, núm. 1 (2017) pp. 89-119. e-ISSN: 2340-2776 http://dx.doi.org/10.12795/rea.2017.i34.04

cc) (i) $\Theta$

SinObraDerivada 4.0 Internacional 
se va a gestionar. El estudio exhaustivo de Portmán y su entorno permite la identificación de los diversos factores biológicos, físicos, patrimoniales y de ordenación que convergen en este territorio.

El objetivo de este trabajo es la identificación y categorización del conjunto de factores aplicables a las posibles actividades asociadas a la recuperación de la bahía, y a los distintos planes de desarrollo planteados para Portmán y la Sierra Minera. Además, se pretende integrar dichos factores posibilitando la definición de los escenarios más propicios y factibles para una planificación con criterios de desarrollo local sostenible y respetuoso con el entorno.

\section{METODOLOGÍA}

\section{1. ÁREA DE ESTUDIO}

El área de trabajo se localiza en la bahía de Portmán, situada en el SE de la Península Ibérica. La bahía forma parte de la Sierra Minera de Cartagena - La Unión, constituyendo el extremo suroriental de la Cordillera Bética. Esta sierra litoral con elevaciones cercanas a los $450 \mathrm{~m}$. de altitud, presenta una serie de relieves acantilados que se extienden de O a E desde la ciudad de Cartagena hasta Cabo de Palos (Manteca y Ovejero, 1992) (Figura 1).

Las peculiaridades climáticas, con temperaturas medias anules próximas a los $20^{\circ} \mathrm{C} y$ escasas precipitaciones con valores próximos a $300 \mathrm{~mm}$ por año, que le confieren unos marcados rasgos de clima semiárido. Entorno que no ha impedido el desarrollo una de la mayor biodiversidad de Europa, con la existencia de varias especies endémicas, que han favorecido la obtención de diversas figuras de protección ambiental como Lugar de Importancia Comunitaria (LIC) y Espacio Natural Protegido para el Parque Regional de Calblanque, Monte de las Cenizas y Peña del Águila, así como una Zona de Especial de Protección para las Aves en la Sierra de la Fausilla.

Desde el punto de vista socioeconómico y cultural, la comarca ha estado ligada a la minería desde la antigüedad, y lo atestiguan importantes restos arqueológicos romanos, como el de la villa romana de Huerta del Paturro (siglos I a IV dc), declarado de utilidad pública en 1973 y Bien de Interés Cultural (BIC) en 1980. Una actividad minera de bajo rendimiento, para la obtención de minerales como blenda, galena, cerusita, casiterita y diversos óxidos de hierro, se ha desarrollado de manera más o menos continua, hasta que finales del siglo XIX, la empresa francesa Société Houillère et Metallurgique de Belmez, constituye la sociedad Minero Metalúrgica de Peñarroya, que se instaló definitivamente en la segunda mitad del siglo XX. En este momento se inicia la verdadera transformación del paisaje natural del entorno de la bahía (Baños-Páez, 2012), escenario de uno de los mayores desastres ambientales del litoral mediterráneo (Martínez-Frias, 1997), con la colmatación de la bahía provocada por el vertido de más de 60 millones de toneladas de estériles de minería al mar durante más de treinta años (Banos-González y Baños-Páez, 2013).

Revista de Estudios Andaluces, vol. 34, núm. 1 (2017) pp. 89-119. e-ISSN: 2340-2776 http://dx.doi.org/10.12795/rea.2017.i34.04 
Figura 1. Ámbito de estudio.

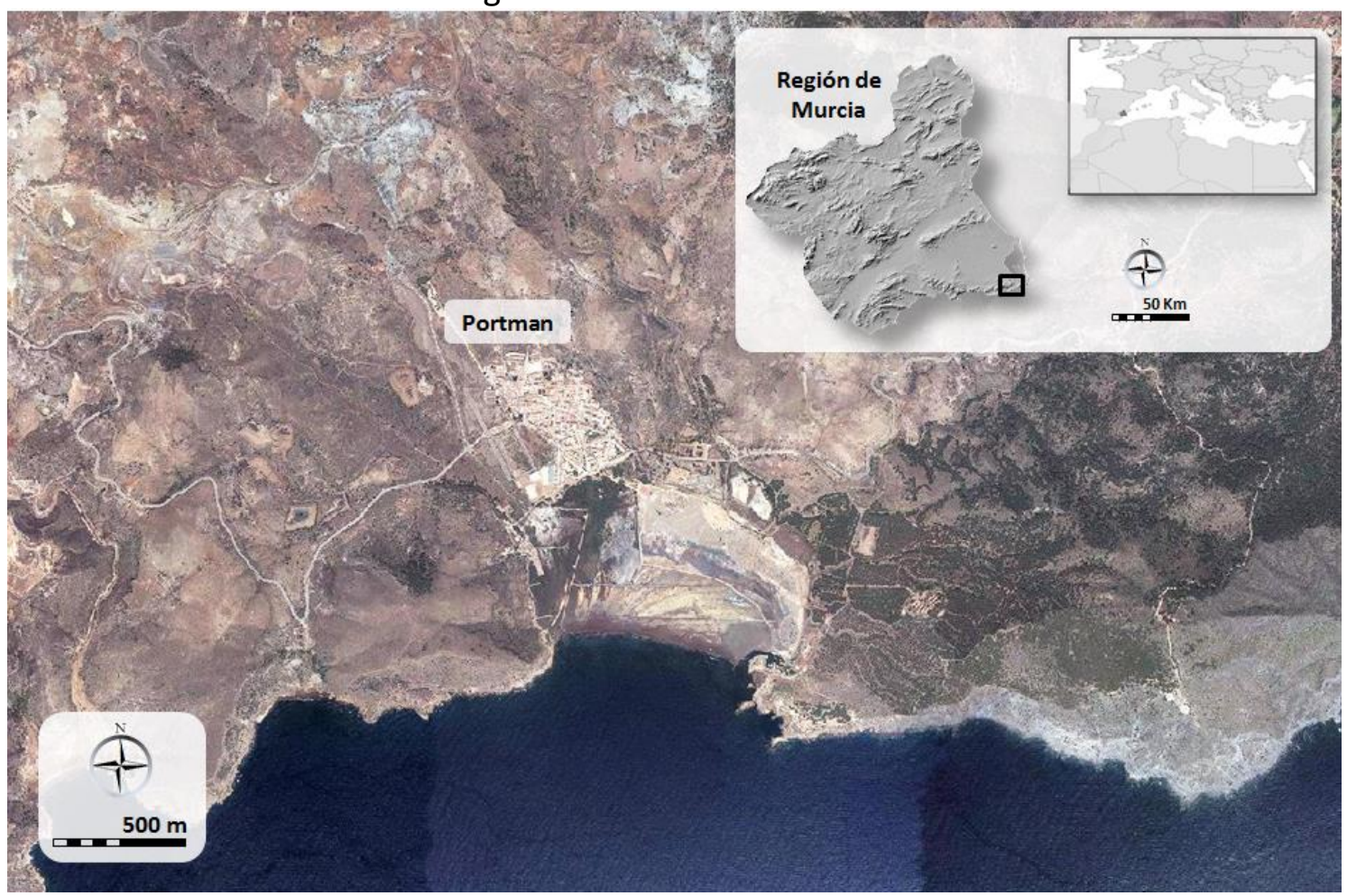

Fuente: Elaboración propia.

Los límites para el análisis de los valores del entorno y el estudio del potencial de desarrollo de la bahía se fijan en los barrancos Del Moro y La Culebra en el extremo occidental (próximos a la bahía del Gorguel), hasta el extremo opuesto, que limita con el Parque Regional de Calblanque, Monte de Las Cenizas y Peña del Águila Lugar de Importancia Comunitaria (LIC) y Espacio Natural Protegido. Como zona de análisis, y para representar los valores del entorno y su potencial de desarrollo se ha asumido la superficie situada entre la costa y la cota de nivel de $100 \mathrm{~m}$., ya que esta zona incluye los alojamientos para la batería de Las Cenizas y la casi totalidad de los elementos de interés para este trabajo.

\subsection{ENFOQUE METODOLÓGICO}

Con el objetivo de plantear opciones de planificación de un desarrollo local sostenible y respetuoso con el entorno, se ha realizado una serie de análisis sectoriales en detalle de todos los condicionantes y limitantes territoriales, ambientales y patrimoniales que se pudieran derivar de las diversas normativas, obligaciones legales y ordenación del suelo aplicables. Como áreas limitantes, han sido definidas aquellas zonas que, por su protección legal o de ordenación, no son compatibles con el aprovechamiento urbanístico. Por otro lado, se han considerado como condicionantes principales aquellas

Revista de Estudios Andaluces, vol. 34, núm. 1 (2017) pp. 89-119. e-ISSN: 2340-2776

http://dx.doi.org/10.12795/rea.2017.i34.04

\section{(c) (i) (3)}

SinObraDerivada 4.0 Internacional 
zonas donde el posible desarrollo de complejos urbanísticos está fuertemente supeditado a la eliminación previa del riesgo minero y la contaminación del suelo, así como para el mantenimiento de los valores naturales del entorno. Mientras que los condicionantes adicionales se corresponden con el conjunto de elementos analizados que, sin estar incluidos en las categorías anteriores, suponen un reconocimiento del valor del territorio, principalmente en cuanto a su patrimonio natural, por su vinculación a tres espacios de la Red Natura 2000, y arqueológico.

Los elementos de análisis territorial se han concentrado en cuatro grandes temáticas: Geomorfología, Ordenación Territorial y Urbanística, Medio Natural y Patrimonio Cultural.

La integración y análisis espacial de todos los condicionantes y limitantes se ha llevado a cabo a través de un sistema de información geográfica (SIG), que ha permitido cuantificar sujeta a los distintos condicionantes y limitantes, y evaluar la importancia de cada uno de los elementos estudiados, y determinar su impacto en el área de estudio.

Con la disponibilidad de una cartografía en detalle y tras el análisis sobre el terreno, se ha llevado a cabo una segunda fase de análisis, con una evaluación global de los usos del suelo que permita determinar los condicionantes y las oportunidades de desarrollo del entorno de Portmán, en el marco de una adecuación a sus características ambientales, patrimoniales y de sostenibilidad.

La combinación de los elementos limitantes, los condicionantes principales y los condicionantes adicionales identificados, permite una visión integral del ámbito estudiado. Para ello se ha empleado una jerarquía espacial según la implicación sobre las aptitudes de uso del territorio, donde el primer nivel se establece a partir de la superficie ocupada por factores limitantes. A continuación, en el ámbito restante se ha incorporado la superficie de condicionantes principales, que mediante su diferencia permite extraer la superficie neta, es decir la superficie que ocupan no coincidente con áreas limitantes. Siguiendo el mismo método, en el ámbito no englobado por limitantes ni por condicionantes principales, se muestra finalmente el área sujeta a los condicionantes adicionales.

\section{RESULTADOS}

\subsection{ANÁLISIS PARCIALES}

\subsubsection{GEOMORFOLOGÍA}

El análisis geomorfológico responde a una situación de profunda trasformación de la Sierra derivada de las actividades mineras, que ha supuesto un conjunto de riesgos asociados a la minería, la erosión y la contaminación del suelo (Figura 2).

Revista de Estudios Andaluces, vol. 34, núm. 1 (2017) pp. 89-119. e-ISSN: 2340-2776 http://dx.doi.org/10.12795/rea.2017.i34.04

$$
\text { (c) }(i) \Theta
$$


Figura 2. Riesgos debidos a la minería.

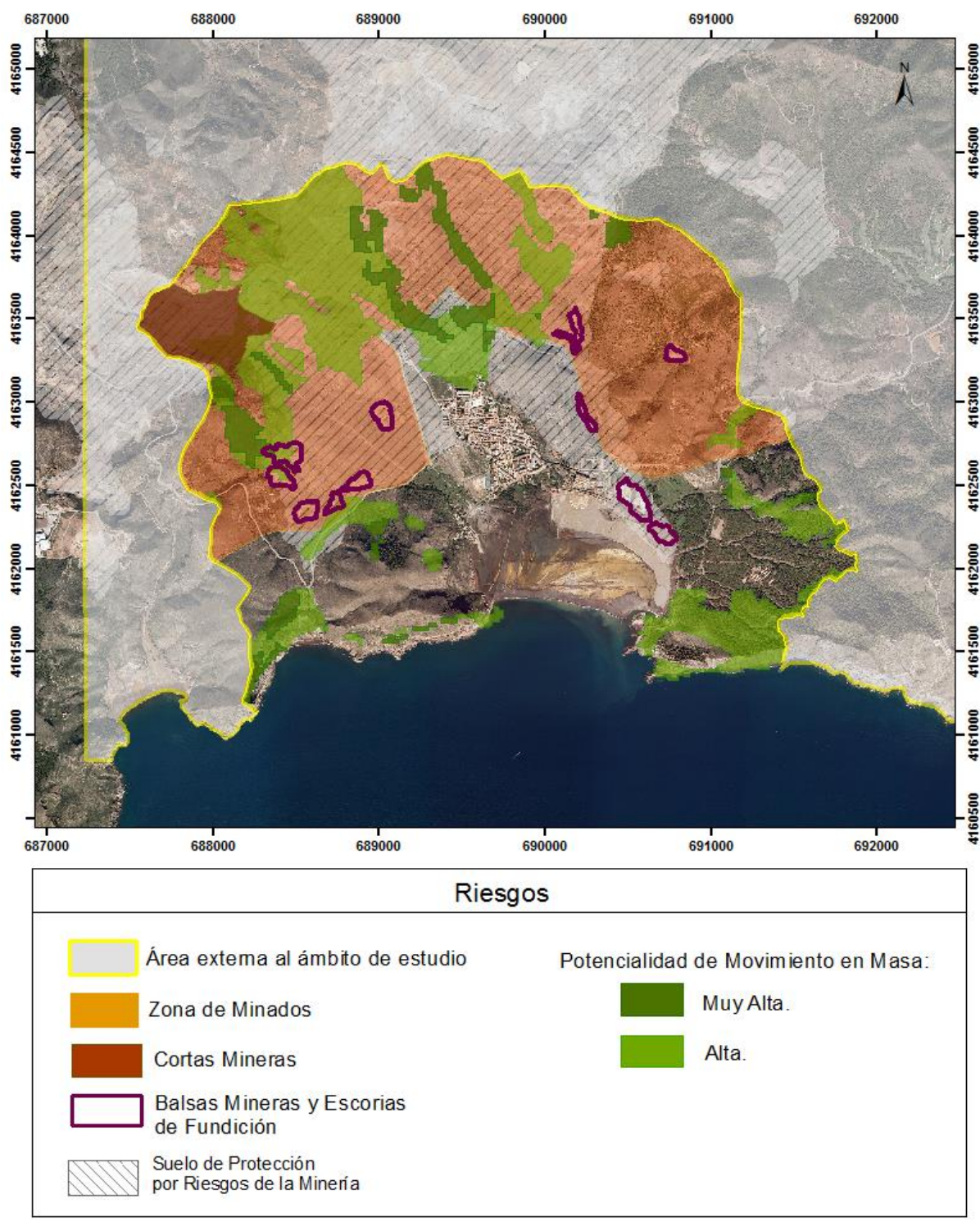

Fuente: Elaboración propia a partir de datos de la Consejería de Turismo y Ordenación del Territorio a través de su aplicación SIT Murcia; el Inventario Nacional de Erosión del Suelo de 2006-2012; Directrices de Ordenación Territorial de Portmán y Sierra Minera; y García et al. (2001).

\section{- Riesgos asociados a la minería y la erosión.}

El 43\% del ámbito de estudio está sometido al régimen de "suelo de protección por riesgos de minería". De acuerdo con las Directrices y Plan de Ordenación Territorial del Litoral de la Región de Murcia (en adelante DPOTL), se trata de terreno propicio a sufrir desprendimientos, avalanchas, hundimientos, o cualquier otro riesgo natural, que implica el establecimiento de limitaciones a su transformación urbanística, pues ésta supondría un riesgo para la seguridad de las personas y los bienes (BORM, 2004). Esta

Revista de Estudios Andaluces, vol. 34, núm. 1 (2017) pp. 89-119. e-ISSN: 2340-2776

http://dx.doi.org/10.12795/rea.2017.i34.04

\section{(c) (i) $(9)$}

SinObraDerivada 4.0 Internacional 
reserva para la transformación de usos en estos suelos queda supeditada a la acreditación de la inexistencia del riesgo ante la Administración competente en materia de ordenación del territorio.

En la zona de estudio, los riesgos asociados a la actividad minera vienen definidos tanto por los residuos generados y su depósito, como por la existencia de estructuras subterráneas del tipo cámaras y pilares (García, 2004). Las numerosas galerías existentes, a pesar de su sellado, condicionan la estabilidad de las edificaciones que sobre ellas se construyan (García et al., 2001). Otras estructuras a considerar son las balsas y pantanos mineros, un total de 11 en el ámbito del trabajo, donde se acumulaban lodos procedentes de los lavaderos en tierra. La infiltración de estos lodos implica riesgos de erosión subterránea al ocasionar grietas e incluso la disolución de la capa cálcica de las balsas, provocando el hundimiento de las masas superiores. El riesgo por desplome es especialmente significativo en las balsas que se encuentran próximas a zonas urbanas. En la planicie próxima al núcleo de Portmán se localizan 4 balsas y, por tanto, el posible desarrollo urbanístico en esta zona requeriría la previa eliminación de todos los riesgos asociados a ellas.

Otro riesgo es la generación de lixiviados de aguas ácidas con alto poder corrosivo que derivan del paso de la escorrentía por zonas de acumulación de residuos, que pueden ocasionar una alta concentración de contaminantes. La erosión y el transporte eólico suponen un aumento de partículas contaminantes en suspensión por la acción de los vientos sobre las áreas de residuos desprovistas de cobertura vegetal. Es particularmente preocupante el transporte de partículas ricas en sulfatos y metales que se forman en las balsas de lodos finos, especialmente en los meses más secos, así como la concentración de metales pesados en el aire, como plomo y zinc, que pueden afectar a la salud de los habitantes de la zona (Belmonte et al., 2010).

También han de considerarse los riesgos sísmicos, a los que se asocia a la actividad minera, en tanto que las mineralizaciones explotadas siguen con frecuencia zonas de fracturación a distintas profundidades. Además, pueden originarse hundimientos por aumento del nivel freático del agua subterránea o por deterioro de las estructuras mineras, sobre todo de aquellas zonas de amplias cámaras, ya que la afección sobre un solo pilar puede derivar en el derrumbe de gran parte de la mina.

La convergencia de este conjunto de riesgos evidencia la complejidad para establecer áreas sin impacto por actividades mineras en el entorno de Portmán, más aún si se considera que, además de aquellas afecciones directas -como los derrumbes-, existen intensos impactos difusos por erosión eólica y lixiviación, que determinan la presencia de altas concentraciones de metales pesados en puntos alejados de su lugar de depósito.

Revista de Estudios Andaluces, vol. 34, núm. 1 (2017) pp. 89-119. e-ISSN: 2340-2776 http://dx.doi.org/10.12795/rea.2017.i34.04 


\section{- Actividad minera y la contaminación del suelo.}

De acuerdo con el Decreto 9/2005, de 14 de enero, por el que se establece la relación de actividades potencialmente contaminantes del suelo y los criterios y estándares para la declaración de suelos contaminados, la extracción de minerales no férreos -como la plata o el zinc-, llevada a cabo en el conjunto de la Sierra, se clasifica como actividad potencialmente contaminante del suelo. De esta forma, toda el área establecida de minados, en la que quedan incluidas las balsas y pantanos de lodos y las escombreras, debería estar considerado como "suelo potencialmente contaminado". La propia normativa ya establece en su artículo 3 la exigencia de presentar un "informe preliminar de situación" a los propietarios de los suelos en los que en el pasado se haya desarrollado alguna actividad potencialmente contaminante, cuando se solicita un cambio de uso del suelo.

\subsubsection{ORDENACIÓN TERRITORIAL Y URBANÍSTICA}

El análisis de la ordenación territorial engloba distintos tipos de régimen de protección del suelo establecidos por las DPOTL, el dominio público y la ordenación urbanística municipal. En cuanto a los regímenes de protección, además de por riesgos de la minería detallada en el apartado anterior, dichas Directrices establecen protección de suelo "de cauces", "geomorfológica por pendientes", "paisajística" y "de protección y defensa nacional".

El régimen de Protección de Cauces persigue responder a la necesidad de controlar los posibles riesgos naturales de inundaciones, para lo que establece una banda de 100 metros a ambos lados de los cauces, en este caso de las ramblas Del Infierno, La Boltada y los barrancos del Moro y la Culebra. Esta delimitación tiene carácter preventivo, por lo que -a partir de un estudio hidrológico e hidráulico- puede admitirse la modificación de esta banda de protección sin perjuicio de la zona de policía establecida en la Ley de Aguas. Sería conveniente que en los mencionados estudios hidráulicos se incorporase el riesgo singular del distrito minero de llegada de lixiviados con altas concentraciones de metales pesados, particularmente destacable en las ramblas mencionadas, ya que puede condicionar la estabilidad de las infraestructuras que se ubiquen en su zona de influencia.

El régimen del suelo de "Protección geomorfológica por pendientes" se aplica sobre áreas con pendientes superiores al 50\%, que constituyen terrenos con condiciones constructivas muy desfavorables y elevada fragilidad paisajística. En cuanto al suelo de "Protección Ambiental", coincidente exactamente con los espacios protegidos de la Red Natura 2000 del ámbito de estudio. 
El suelo protegido por "Protección y Defensa Nacional", engloba la Batería de La Chapa, en el extremo suroriental de la bahía. A pesar de que se mantiene en la información cartográfica oficial de las DPOTL, conviene puntualizar que desde 2006 esta zona pasó a ser competencia del Ministerio de Medio Ambiente.

En relación al Dominio Público, cabe señalar que según la información analizada de la Confederación Hidrográfica del Segura, en la actualidad no existe delimitado el Dominio Público Hidráulico en la zona de estudio, dado que no se ha efectuado el deslinde por parte de la Administración competente, por lo que no ha podido ser considerado. La Ley 13/2015, de Ordenación Territorial y Urbanística de la Región de Murcia, determina que los Planes de Desarrollo, responsabilidad de los promotores de los proyectos que se planteen en el ámbito, deben incluir el dominio público, previo informe del Órgano de Cuenca.

Respecto a la superficie de Dominio Público Marítimo Terrestre, queda clasificada por parte de la Administración como suelo no urbanizable. Además, en la zona de servidumbre de protección de 100 metros, según la Ley de Costas 22/1988, quedan prohibidas las edificaciones destinadas a residencia o habitación, entre otras limitaciones. La reducción del ancho de esta servidumbre de 100 a 20 metros en relación con los núcleos de población que plantea la ley 2/2013, de 29 de mayo, de protección y uso sostenible del litoral y de modificación de la Ley 22/1988, no tiene efecto en la zona de estudio.

En cuanto a las Vías Pecuarias, según la documentación oficial, no queda incluida ninguna en el ámbito de estudio. No obstante, junto a la carretera N-345, en la zona de acceso a la Cala del Caballo, aún se conserva el aprisco del Corralón, tradicionalmente empleado como lugar de descanso del ganado durante la época invernal, lo que supondría la posible existencia de una vía pecuaria no identificada oficialmente.

Por último, con relación a la ordenación urbanística vigente, actualmente está referida a las Normas Subsidiarias de La Unión, y al Plan General Municipal de Ordenación de Cartagena (BORM, 2012). De estos planes, se deduce la restricción de la clasificación del suelo como urbano o urbanizable en al ámbito de estudio, limitándose estas clases de suelo casi en exclusiva al núcleo de Portmán y sus inmediaciones. El distrito minero circundante está clasificado como Suelo No Urbanizable, de forma coherente a los diversos riesgos derivados de la actividad minera recogidos en el apartado anterior. En la Normas Subsidiarias de La Unión se clasifica como No urbanizable protegido (área minera), mientras que en el Plan General de Cartagena se considera No urbanizable inadecuado. Asimismo, reconociendo la singularidad ambiental de la zona, otro amplio porcentaje de suelo se clasifica como Suelo No Urbanizable de Protección Específica (por Protección Ambiental). En el extremo oriental, perteneciente a Cartagena, esta clasificación coincide con la fracción del LIC Calblanque, Monte de las Cenizas y Peña del Águila. El área encerrada entre el límite de este espacio y el de la propia bahía también 
se recoge como suelo No Urbanizable, en el que se incluye suelo No Urbanizable de Protección Específica de Costas y suelo No Urbanizable Inadecuado.

En cuanto a la ordenación urbanística de La Unión, es necesario apuntar que en 2005 se sometió a información pública la propuesta de Plan General de Ordenación Municipal, con aprobación inicial en 2006, cuyo trámite quedó posteriormente interrumpido. En esta propuesta, toda el área minera -que en las Normas Subsidiarias se recogía como suelo No Urbanizable Protegido-, quedaba clasificada como suelo Urbanizable de Mínima Densidad. En este sentido, dada la regulación antes descrita de las DPOTL, el desarrollo urbanístico estaría, en todo caso, supeditado a la acreditación de inexistencia de los riesgos derivados de la minería (relacionados con la estabilidad y seguridad del terreno, pero también con la contaminación del suelo por metales pesados).

\subsubsection{MEDIO NATURAL}

Para el análisis del medio natural vinculado al entorno de Portmán, se han considerado cinco subapartados:

\section{- Espacios Protegidos “Red Natura 2000".}

En el entorno de Portmán se encuentran tres espacios protegidos de la Red europea "Natura 2000":

- ZEPA ES0000199 Sierra de La Fausilla, al suroeste, designada por su población de Camachuelo trompetero (Bucanetes githagineus). Además, se localizan áreas de nidificación de tres grandes rapaces: Búho real (Bubo bubo), Halcón peregrino (Falco peregrinus) y Águila-azor perdicera (Hieraaetus fasciatus).

- LIC ES6200025 Sierra de La Fausilla, cuyos límites no coinciden exactamente con los de la ZEPA anterior. Se caracteriza en líneas generales por una gran diversidad de ambientes, destacando el cornical (Periploca angustifolia), en muy buen estado de conservación, la vegetación de tomillar y los hábitats rupícolas asociados a los escarpes litorales.

- LIC ES6200001 y Espacio Natural Protegido Calblanque, Monte de las Cenizas y Peña del Águila, que ocupa todo el extremo oriental del ámbito de estudio. Es un enclave excepcional en Europa, por ser la única localidad de Sabina de Cartagena (Tetraclinis articulata) en estado natural. En su porción asociada a la Sierra Minera pueden encontrarse, además, especies de elevado interés como la especie endémica Limonium carthaginensis.

Entre estos espacios de la Red Natura 2000, ocupando una importante superficie de la Sierra Minera y prácticamente la totalidad del ámbito de estudio, se extiende el corredor ecológico número 47 de la Red de Corredores Ecológicos de la Región de Murcia. Este

Revista de Estudios Andaluces, vol. 34, núm. 1 (2017) pp. 89-119. e-ISSN: 2340-2776 http://dx.doi.org/10.12795/rea.2017.i34.04

\section{(c) (i) (3)}

SinObraDerivada 4.0 Internacional 
amplio corredor, de 3625,41 hectáreas, establece la conectividad para diversas asociaciones vegetales de gran singularidad en el contexto europeo como la correspondiente a los Bosquetes de Tetraclinis (hábitat 9570) o a los cornicales de Periploca angustifolia y Maytenus senegalensis subsp. europaea (hábitat 5220). Para los espacios pertenecientes a la Red Natura 2000, los Criterios Técnicos Orientadores del Medio Natural de la Dirección General de Medio Ambiente de la Región de Murcia, establecen una banda perimetral de amortiguación de $100 \mathrm{~m}$. como mínimo, y una zona de influencia mínima de $500 \mathrm{~m}$. que se extiende hasta los $1000 \mathrm{~m}$. debido a la presencia en zonas limítrofes de especies vulnerables ligadas a estos espacios.

\section{- Hábitats de interés comunitario, incluidos hábitats calificados como "prioritarios".}

El ámbito de estudio muestra una gran extensión de manchas de vegetación perteneciente a hábitats de interés comunitario, en especial los calificados como "prioritarios" por la Directiva Hábitats 92/43/CEE. Además, es probable que el cese de la actividad minera y la escasa trasformación de usos del suelo desde entonces, haya permitido una mejora en su desarrollo de forma continua (Figura 3). Quizá por ello, los hábitats de interés comunitario y prioritarios presentes en los espacios de la Red Natura se extienden en las áreas naturales colindantes, llegando a conectarlos. Así, actualmente, existe conectividad natural entre los espacios de la Red, en consonancia con lo previsto en el artículo 46 de la Ley 42/2007, de 13 de diciembre, de Patrimonio Natural y Biodiversidad, que recoge la importancia de conservar y restaurar estos elementos de conexión con el objetivo de asegurar su funcionalidad. Esta banda continua de vegetación justifica la existencia del corredor ecológico descrito.

Entre los hábitats presentes en la zona de estudio (Tabla 1), destacan los prioritarios y muy raros correspondientes a Matorrales arborescentes de Ziziphus (hábitat 5220*), caracterizado por Periploca angustifolia y Maytenus senegalensis subsp. europea, y Bosques de Tetraclinis articulata (hábitat 9570*), cuya especie presenta una distribución destacada en la Peña del Águila, y también en la Sierra Minera y proximidades de Portmán.

Según el Acuerdo de la Comisión Técnica Española de la Red Natura 2000 (Baraza, 1999), en relación a la representatividad de los hábitats de la Directiva 92/43/CEE, la superficie de hábitats muy raros debe estar integrada al 100\% en la Red Natura 2000, independientemente de su estado de conservación. De esta forma, toda la superficie de los hábitats 5220*, 9570* y 1240 presentes en el ámbito de Portmán, deben estar sometidos a medidas de conservación y propuesta su integración a la Red Natura 2000. En concreto, los hábitats 5220* y 9570* muestran un alto potencial de distribución en la zona, como evidencia la existencia de cornicales en desarrollo en las laderas del Monte del Pino y el Plan de Gestión del Tetraclinis articulata (Esteve et al., 2010), respectivamente.

Revista de Estudios Andaluces, vol. 34, núm. 1 (2017) pp. 89-119. e-ISSN: 2340-2776 http://dx.doi.org/10.12795/rea.2017.i34.04

c) (i) $(9)$

cc) Esta obra se distribuye con la licencia Creative Commons Reconocimiento-NoComercialSinObraDerivada 4.0 Internacional 
Patricia Esteve-Guirao, Isabel Banos-González, Pedro Baños-Páez, Pedro Pérez-Cutillas, Emilio Díez de Revenga-Martínez, Magdalena Martínez-Pedrero y María Lluna-Díaz

Figura 3. Hábitats de interés comunitario presentes en la zona de estudio.

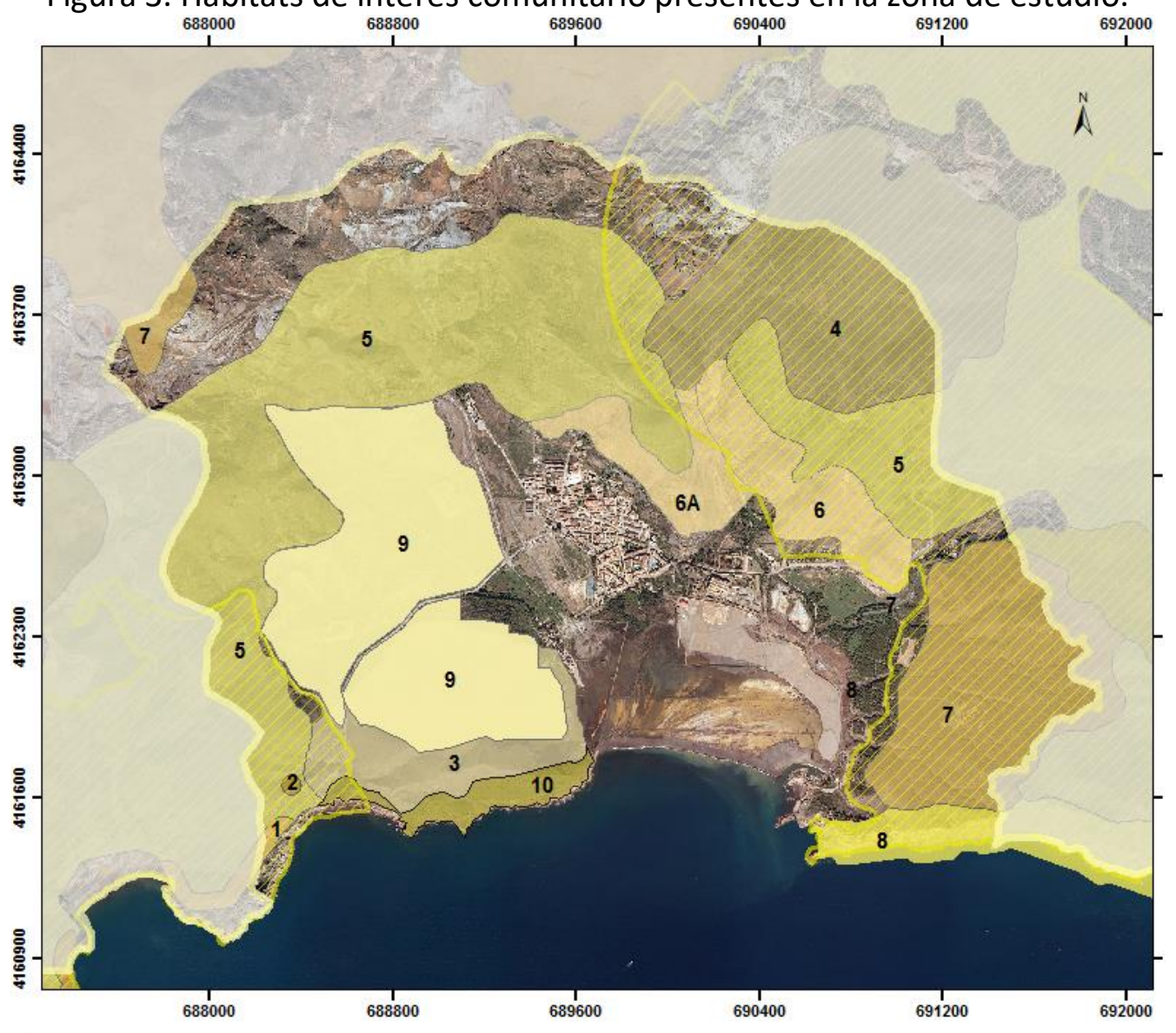

\begin{tabular}{|c|c|c|c|}
\hline \multicolumn{4}{|c|}{$\begin{array}{l}\text { HÁBI TATS NATURALES Y SEMINATURALES } \\
\text { DE INTERÉS COMUNI TARIO. }\end{array}$} \\
\hline \multicolumn{2}{|c|}{ Hábitats ( ${ }^{*}$ ind ica priorid ad) } & \multicolumn{2}{|c|}{ Elaboración propia: } \\
\hline 1 & 1240 & $6 \mathrm{~A}$ & $5220^{*}, 5330$ y $9570^{*}$ \\
\hline 2 & 5330 y 8210 & & $5220^{*}, 5330,6220^{*}$ y $9570^{*}$ \\
\hline 3 & 1240,5330 y $6220^{*}$ & 10 & 1240 y 5330 \\
\hline 4 & $5330,6220^{*}$ y $9570^{*}$ & \multirow{3}{*}{\multicolumn{2}{|c|}{ Lugares de Importancia Comunitaria }} \\
\hline 5 & $5220^{*}, 5330,6220,8210$ y $9570^{*}$ & & \\
\hline 6 & $5220^{*}, 5330$ y $9570^{*}$ & & \\
\hline 7 & 5330 y $6220^{*}$ & \multirow{2}{*}{\multicolumn{2}{|c|}{ Área externa al ámbito de estudio }} \\
\hline 8 & $5220^{*}, 5330,6220^{*}$ y 8210 & & \\
\hline
\end{tabular}

Fuente: Elaboración propia a partir de información del Geocatálogo de la Dirección General de Medio Ambiente; el Atlas de Hábitats Naturales y Seminaturales de España del Ministerio de Medio Ambiente, Medio Rural y Marino 2001-2004; y datos procedentes de prospecciones de campo.

Revista de Estudios Andaluces, vol. 34, núm. 1 (2017) pp. 89-119. e-ISSN: 2340-2776 http://dx.doi.org/10.12795/rea.2017.i34.04

\section{c) (1) $\Theta \odot$}

SinObraDerivada 4.0 Internacional 
Tabla 1. Hábitats de interés comunitario y prioritarios presentes en el ámbito de estudio.

\begin{tabular}{l}
\begin{tabular}{|l|l|}
\hline CATEGORÍA DE LOS HABITATS PRESENTES EN LOS ESPACIOS NATURA 2000 Y EN LAS \\
ÁREAS LIMÍTROFES \\
\hline Muy raros y prioritarios & $\begin{array}{l}5220 * \text { Matorrales arborescentes de Ziziphus. } \\
9570 * \text { Bosques de Tetraclinis articulata. }\end{array}$ \\
\hline Muy raro y no prioritario & $\begin{array}{l}1240 \text { Acantilados con vegetación de las costas } \\
\text { mediterráneas con Limonium spp. endémicas }\end{array}$ \\
\hline Raro y no prioritario & $\begin{array}{l}8210 \text { Pendientes rocosas calcícolas con vegetación } \\
\text { camofítica. }\end{array}$ \\
\hline No raro y prioritario & $\begin{array}{l}6220 * \text { Zonas subestépicas de gramíneas y anuales del } \\
\text { Thero-Brachypdietea. }\end{array}$ \\
\hline No raro y no prioritario & 5330 Matorrales termomediterráneos y pre-estépicos \\
\hline
\end{tabular} \\
\hline
\end{tabular}

Esta potencialidad en la zona y su excelente grado de conservación, unido a la escasa extensión a escala nacional de estos hábitats, también determinaría la inclusión en la Red Natura 2000 de estas zonas.

Por otra parte, los Criterios Técnicos Orientadores en Materia de Medio Natural consideran que causarán un impacto ambiental crítico inasumible aquellos proyectos que supongan la desaparición de una superficie significativa (mayor a una hectárea) de tipos de hábitats de interés comunitario calificados como "Prioritarios" y "Raros o Muy Raros" (hábitats 1240, 5220, 6220, 8210 y 9570). La gran extensión en todo el territorio de estudio de estos cinco hábitats evidencia la importancia de este criterio.

Estos Criterios Técnicos también establecen que, en planes y actuaciones urbanísticas y turísticas, los terrenos con valores naturales no incluidos en espacios protegidos como hábitats prioritarios, poblaciones reconocibles de especies protegidas (como el caso de los bosquetes de Sabina de Cartagena o cornicales, entre otras), deberán ser clasificados como Suelo No Urbanizable en el Planeamiento.

\section{- Especies catalogadas de flora silvestre.}

La Sierra Minera, a pesar de la intensa trasformación, alberga todo un conjunto de especies exclusivas, raras o amenazadas. Sobre las especies presentes en el ámbito de estudio, que quedan recogidas en el Catálogo Regional de Flora Silvestre Protegida (Tabla 2), deberán aplicarse normas especiales de protección (Decreto 50/2003) y se dictan normas para el aprovechamiento de diversas especies forestales.

El ámbito de estudio y el conjunto del distrito de la Sierra Minera, constituye el núcleo principal de especies endémicas de las sierras litorales murcianas como Teucrium carthaginense, Teucrium freynii y Limonium carthaginenesis. Asimismo, los bosques naturales presentes de Tetraclinis articulata, con más de 2000 ejemplares, conforman las últimas poblaciones en todo el continente europeo. Según la Ley de Patrimonio

Revista de Estudios Andaluces, vol. 34, núm. 1 (2017) pp. 89-119. e-ISSN: 2340-2776 http://dx.doi.org/10.12795/rea.2017.i34.04 
Natural y Biodiversidad (Ley 42/2007), en su artículo 54, "queda prohibida la destrucción intencionada de la especie en la naturaleza, así como recogerla, cortarla, mutilarla, arrancarla". Esta prohibición condicionaría las actuaciones allí donde se encuentre la especie.

Tabla 2. Especies de flora silvestre del entorno de Portmán incluidas en el Catálogo Regional de Flora Silvestre Protegida.

\begin{tabular}{|c|c|}
\hline & SPECIES DE FLORA AMENAZADA \\
\hline \multirow{8}{*}{$\begin{array}{l}\text { ESPECIES } \\
\text { VULNERABLES }\end{array}$} & Allium melananthum \\
\hline & Lafuentea rotundifolia \\
\hline & Limonium carthaginenese \\
\hline & Maytenus senegalensis subsp. europaea \\
\hline & Periploca angustifolia \\
\hline & Salsola papillosa \\
\hline & Tetraclinis articulata \\
\hline & Teucrium carthaginense \\
\hline \multirow{8}{*}{$\begin{array}{l}\text { ESPECIES DE INTERÉS } \\
\text { ESPECIAL }\end{array}$} & Chamaerops humilis \\
\hline & Clematis cirrhosa \\
\hline & Limonium cossonianum \\
\hline & Osyris lanceolada \\
\hline & Rhamnus alaternus \\
\hline & Rhamnus lycioides subsp.borgiae \\
\hline & Sideritis pusilla subsp. carthaginenesis \\
\hline & Teucrium freynii \\
\hline
\end{tabular}

Fuente: Catálogo Regional de Flora Silvestre Protegida (2003).

La presencia de estas especies protegidas en los espacios de la Red Natura 2000 del ámbito y en áreas de vegetación circundantes, conlleva la aplicación de los Criterios Técnicos Orientadores en Materia de Medio Natural, que especifican que quedarán incluidas dentro de la zona de influencia de los espacios de la Red Natura aquellas zonas limítrofes a cada espacio, situadas entre los 500 metros y 1000 metros, que contengan en su interior especies de fauna y/o flora ligadas al espacio protegido y que estén catalogadas como "en peligro de extinción", "sensible a la alteración de su hábitat" o "vulnerable". De esta forma, al relacionar los espacios Natura 2000 y las especies catalogadas como "vulnerables" descritas para las zonas limítrofes, la zona de influencia de los LIC se extiende hasta los $1000 \mathrm{~m}$. Para su representación cartográfica, los límites se han precisado excluyendo el núcleo urbano de Portmán (Figura 4). 
Figura 4. Vegetación e incendios en el entorno de Portmán.

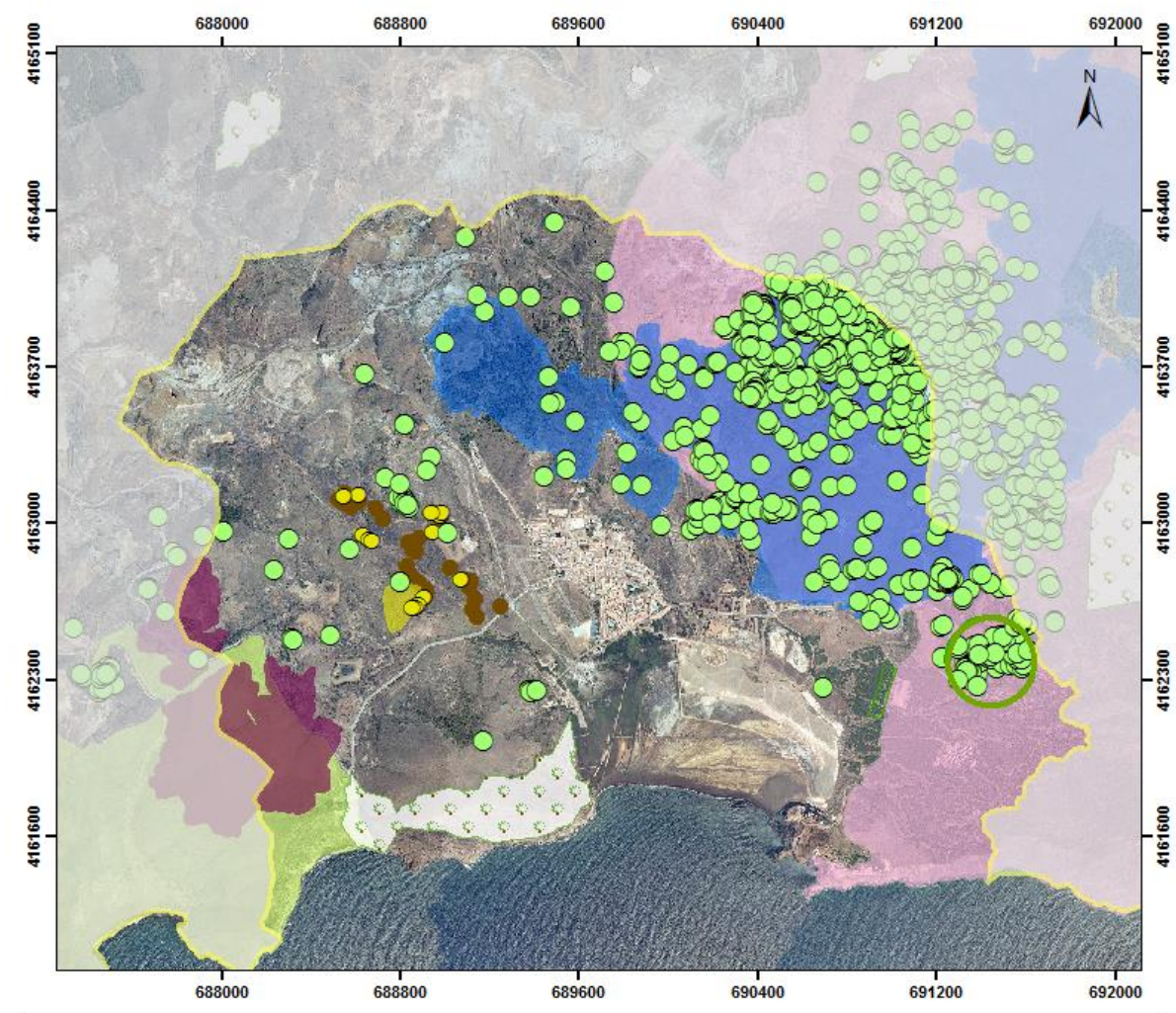

VEGETACIÓN E INCENDIOS

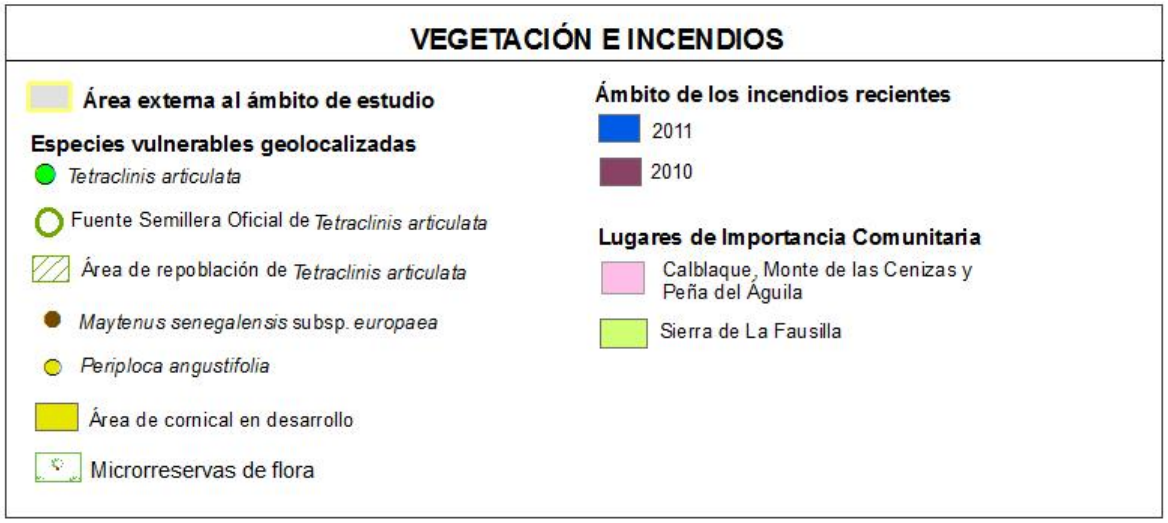

Fuente: Elaboración propia a partir de datos procedentes de Esteve et al. (2010); estudios inéditos del Departamento de Ecología de la Universidad de Murcia relativos al incendio de 2011; el Geocatálogo de la Dirección General de Medio Ambiente; y prospecciones de campo.

\section{- Aves rapaces amenazadas.}

En el ámbito de estudio quedan integrados puntos de nidificación de 5 parejas de rapaces amenazadas: 3 parejas de Bubo bubo (Búho real), una pareja de Falco peregrinus (Halcón peregrino), y otra pareja de Hieraaetus fasciatus (Águila-azor perdicera).

Según la Ley 7/1995, de 21 de abril, de Fauna Silvestre de la Región de Murcia, todos los puntos de nidificación de Hieraaetus fasciatus conforman "áreas de protección de fauna silvestre". En el caso del área de estudio, ya se encuentra incluido en los escarpes

Revista de Estudios Andaluces, vol. 34, núm. 1 (2017) pp. 89-119. e-ISSN: 2340-2776 http://dx.doi.org/10.12795/rea.2017.i34.04 (c) (i) (3) 
litorales de la ZEPA Sierra de La Fausilla, donde también se localiza una pareja de Bubo bubo y una de Falco peregrinus. Con posterioridad, el Decreto 59/2016, de 22 de junio, aprueba el Plan de Recuperación de Hieraaetus fasciatus, estableciendo el área del Monte de las Cenizas también como "áreas de protección de fauna silvestre".

Fuera de los espacios protegidos de la Red Natura 2000, según datos del Departamento de Ecología e Hidrología de la Universidad de Murcia, se emplazan dos nidos de Búho real. Esta especie está incluida en el anexo I de la Directiva Aves, que implica que requiere medidas de protección y conservación especiales, y en el Anexo II del Convenio de Berna, que prohíbe el deterioro o destrucción de sus lugares de reproducción o reposo. Estas normativas tendrán que estar consideradas en las propuestas de actuación que pudieran plantearse en las cercanías de los puntos de nidificación de la especie. No obstante, dado que ocupan áreas con fuertes pendientes, es poco probable que vayan a ser directamente alterados por complejos urbanísticos.

\section{- Incendios.}

Este último apartado se centra en los incendios ocurridos en los años 2010 y 2011, aunque cabe destacar la concurrencia de los incendios en la zona desde 1992, a partir de la protección de Peña del Águila, que han afectado particularmente a la población de Tetraclinis articulata, con más del $40 \%$ de afección sobre las poblaciones de Ponce, Peña, Moro y Campana. El Cabezo de La Galera también sufrió un incendio, cuyos límites ya son difíciles de distinguir dada la excelente regeneración de la cubierta vegetal. El desarrollo vegetal tras este incendio demuestra el potencial de restauración de la zona.

El incendio de 2010, debido a una negligencia durante las labores de mantenimiento de infraestructuras, afectó a 52,25 Ha. que aún hoy son identificables (Figura 4). Asimismo, se aprecia la regeneración de la cubierta vegetal, destacando la recuperación de los palmitos (Chamaerops humilis). En agosto de 2011, tuvo lugar un incendio intencionado en Peña del Águila y, por tanto, considerado como un Delito Ambiental. Significó la afección de 385,44 Ha. de elevado valor natural por la presencia de los bosques de Sabina de Cartagena (Figura 4). Además, suscitó la elaboración de un Plan de Regeneración para esta especie, en competencia con el Pinus halepensis, ya que la pérdida de las masas de pino favorece el crecimiento de la sabina por sus características heliófilas, lo que fortalecerá la población actual.

La Ley 43/2003 de Montes, en su artículo 50, determina que "las comunidades autónomas deberán garantizar las condiciones para la restauración de los terrenos forestales incendiados y queda prohibido el cambio de uso forestal al menos durante 30 años y toda actividad incompatible con la regeneración de la cubierta vegetal, durante el periodo que determine la legislación autonómica", que aún no se ha desarrollado en 
el caso de la Región de Murcia. Respecto a esta prohibición, en el caso concreto de La Unión, no ha lugar a las excepciones estipuladas en la Ley 21/2015, de 20 de julio, por la que se modifica la Ley $43 / 2003$, ya que, con anterioridad al incendio, el instrumento de planeamiento (en el caso de La Unión, el Plan General de Ordenación) no estaba aprobado, y la propuesta en aprobación inicial del año 2005, tal como era exigible, no ha sido objeto de evaluación ambiental favorable.

La importancia del mantenimiento del uso forestal expresado en esta Ley es especialmente relevante en el caso del Tetraclinis articulata. A partir del incendio de 1992, existen datos sobre la respuesta de la especie frente al fuego en esta zona (López et al., 1995). La mortalidad está por debajo del $1 \%$ en ejemplares jóvenes y adultos, con rebrotes tardíos. Las tasas de crecimiento se reducen significativamente (del $12 \%$ a $1,7 \%)$, pero la supervivencia de individuos maduros tiene gran significación en el mantenimiento de la población original, ya que la probabilidad de fruto y la productividad de semillas son mayores, y pueden suponer la recuperación y el crecimiento paulatino de la población, máxime considerando el Plan de Regeneración (Esteve et al., 2010)

\subsubsection{PATRIMONIO CULTURAL}

El área de estudio se encuentra localizada en un entorno altamente transformado por la actuación del ser humano asociada a las actividades mineras, y caracterizada por la existencia de cortas mineras y restos de distintas infraestructuras, residencias y herramientas usadas a lo largo de los siglos. Podría considerarse que el bien patrimonial más importante y extenso es el que constituye el paisaje de la Sierra Minera en su conjunto.

Para el análisis de las implicaciones derivadas de estos valores arqueológicos y culturales se han considerado los Bienes de Interés Cultural declarados y propuestos, los yacimientos arqueológicos, los Lugares de Interés Geológico (LIGs) y Bienes Catalogados (Figura 5).

- Bienes de Interés Cultural declarados y propuestos. Han sido declarados hasta ahora un total de cinco: Huerta del Paturro y Balsas Romanas, que constituye una villa de carácter industrial para el comercio de salazones de los siglos III-IV d.C., y donde se encontraron, entre otros, varios mosaicos y una cabeza de sátiro; la Batería de costa C-8 "La Chapa"; el Hospital de la Caridad, reconvertido en el museo arqueológico de Portmán, y la Casa del Tío Lobo o de Zapata, pendiente aún de rehabilitar.

- En cuanto a la propuesta de Bien de Interés Cultural (BIC) del Paisaje Minero, en mayo de 2006 se hace pública la propuesta para hacer efectiva la declaración de BIC. Aunque posteriormente se declara la caducidad y se archiva el expediente relativo a esta primera delimitación, se ha considerado en este estudio como

Revista de Estudios Andaluces, vol. 34, núm. 1 (2017) pp. 89-119. e-ISSN: 2340-2776 http://dx.doi.org/10.12795/rea.2017.i34.04 


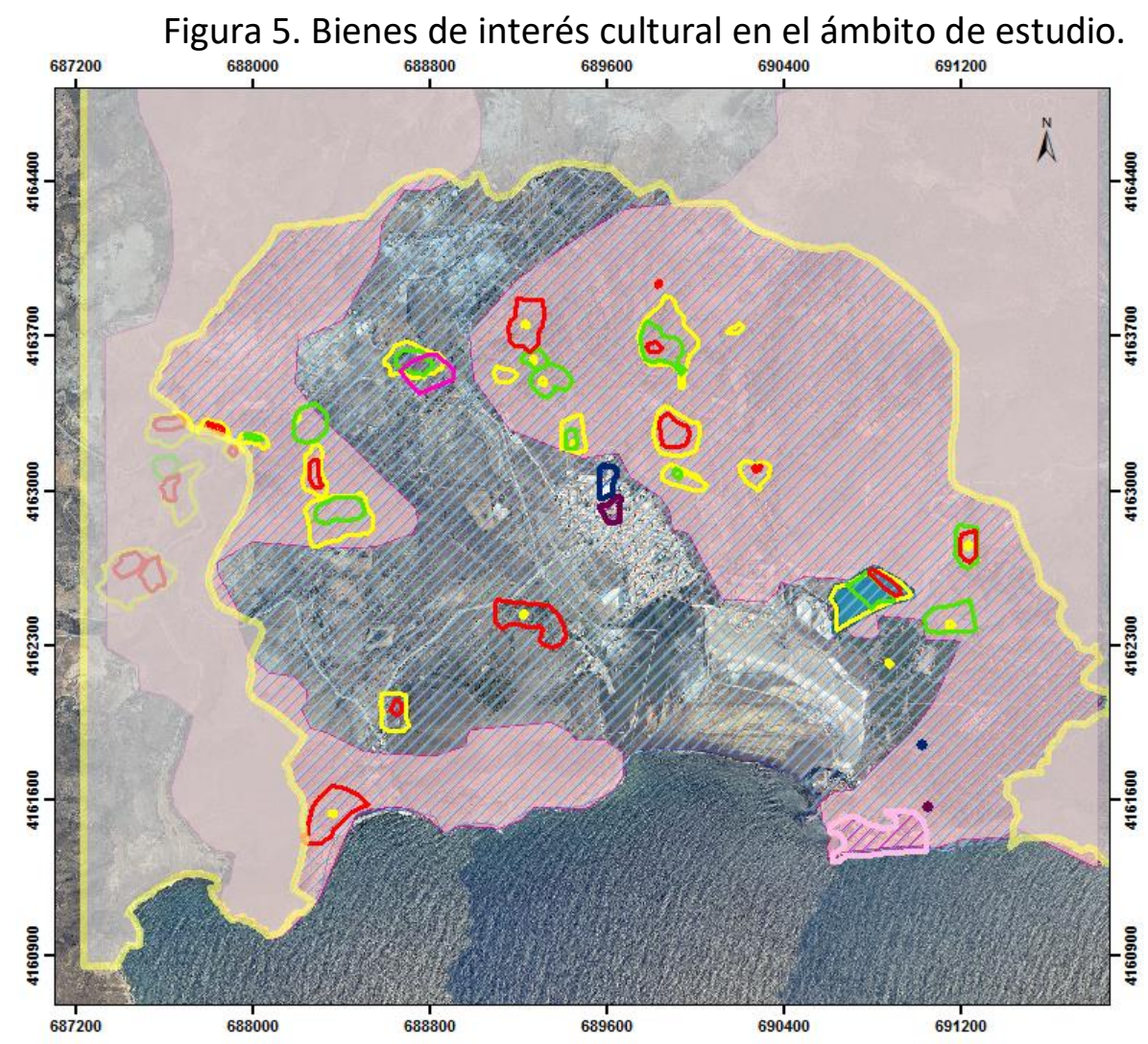

\begin{tabular}{|c|c|c|}
\hline \multicolumn{3}{|c|}{$\begin{array}{l}\text { PATRIMONIO GEOLÓGIĆO } \\
\text { ARQUEOLÓGICO Y ETNOLÓGICO }\end{array}$} \\
\hline & Área externa al ámbito de estudio & Bienes de Interés Cultural Propuestos \\
\hline & Área potencial de patrimonio cultural & Palsaje Minero \\
\hline \multicolumn{2}{|c|}{ Bienes de Interés Cultural Declarados } & $\begin{array}{l}\text { Grados de Protección A rqueológica } \\
\text { de los Yacimientos }\end{array}$ \\
\hline VIII & Bateria C8 "La Chapa" & Grado $A$ \\
\hline 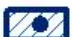 & Hos pital de la Caridad & Grado B \\
\hline 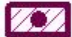 & Casa Tío Lobo & Grado C \\
\hline & BIC Huerta del Paturro y Balsas Romanas & Lugares de Interés Geológico \\
\hline & & Sierra Minera \\
\hline
\end{tabular}

Fuente: Elaboración propia según información de la Consejería de Educación y Cultura de la Región de Murcia; y la Carta Arqueológica Regional de la Dirección General de Bellas Artes y Bienes Culturales.

área potencial de interés cultural. En diciembre de 2006, se declara la delimitación del territorio BIC. Ésta determina un conjunto de implicaciones según la Ley 16/1985 del Patrimonio Histórico Español, que en su artículo 36 menciona que "Los bienes integrantes del Patrimonio Histórico Español deberán ser conservados, mantenidos y custodiados por sus propietarios o, en su caso, por los titulares de derechos reales o por los poseedores de tales bienes". Además, la Ley 4/2007, de 16 de marzo, de Patrimonio Cultural de la Comunidad Autónoma

Revista de Estudios Andaluces, vol. 34, núm. 1 (2017) pp. 89-119. e-ISSN: 2340-2776

http://dx.doi.org/10.12795/rea.2017.i34.04

\section{(c) (i) (3)}

SinObraDerivada 4.0 Internacional 
de la Región de Murcia, contempla en su articulado la relación que la declaración de bienes culturales guarda con el planeamiento urbanístico.

- Yacimientos arqueológicos. Se han considerado aquellos reflejados en la Carta Arqueológica de la Región de Murcia más actualizada. Estos yacimientos se clasifican en tres grados de protección arqueológica según su entidad; siendo las áreas de Grado A las de mayor protección y las de Grado C las de menor, pudiendo concurrir en la misma zona (Figura 5).

- Lugares de Interés Geológico. En cuanto al Patrimonio Geológico en general, son numerosos los lugares que tienen un alto valor geológico, ya que se encuentran afloramientos que poseen un notable interés estratigráfico, petrológico, tectónico, geo-morfológico, mineralógico, etc (Manteca, 2013). Entre los LIGs situados en el entorno de la bahía de Portmán, destacan: la cala de El Gorguel y barranco del Avenque, la Cala del Caballo, los acantilados de Punta Galera, los flancos oriental y occidental de la bahía de Portmán, el sector de la playa del Lastre y acantilados de La Chapa, y la montera de hierro de La Crisoleja.

\subsection{ANÁLISIS GLOBAL DEL TERRITORIO: CONDICIONANTES Y LIMITACIONES}

Los análisis sectoriales presentados en este trabajo, proporcionan una visión del espacio en todo su conjunto, que permite definir categorías territoriales en relación a los posibles desarrollos en forma de proyectos residenciales y turísticos. Estas categorías quedan definidas como: limitantes, condicionantes principales y condicionantes adicionales.

\subsubsection{LIMITANTES}

En el espacio de estudio, estas áreas limitantes presentan superposiciones entre sí, que han sido consideradas para el cálculo de la superficie neta, que alcanza las 566,36 Ha. Esto supone que el $60,45 \%$ del ámbito de estudio no presenta opción alguna para desarrollos residenciales o de alojamientos turísticos, en las condiciones de legislación y normativas vigentes durante este estudio (Figura 6). Dentro de esta categoría se incluyen:

- Dominio Público Marítimo Terrestre (80,37 Ha.), se considera limitante ya que debe ser clasificada por parte de la Administración como suelo no urbanizable. Además de la bahía, se ha incluido toda la línea de costa, a partir de los datos de localización de los mojones del Dominio Público Marítimo-Terrestre.

- Zona de Servidumbre de Protección (25,9 Ha.), pues en ella quedan prohibidas las edificaciones destinadas a residencia o habitación. No obstante, esta zona puede dotarse de servicios para el acceso a la playa, como aparcamientos y otros. 
Figura 6. Categorías limitantes para el desarrollo urbanístico.
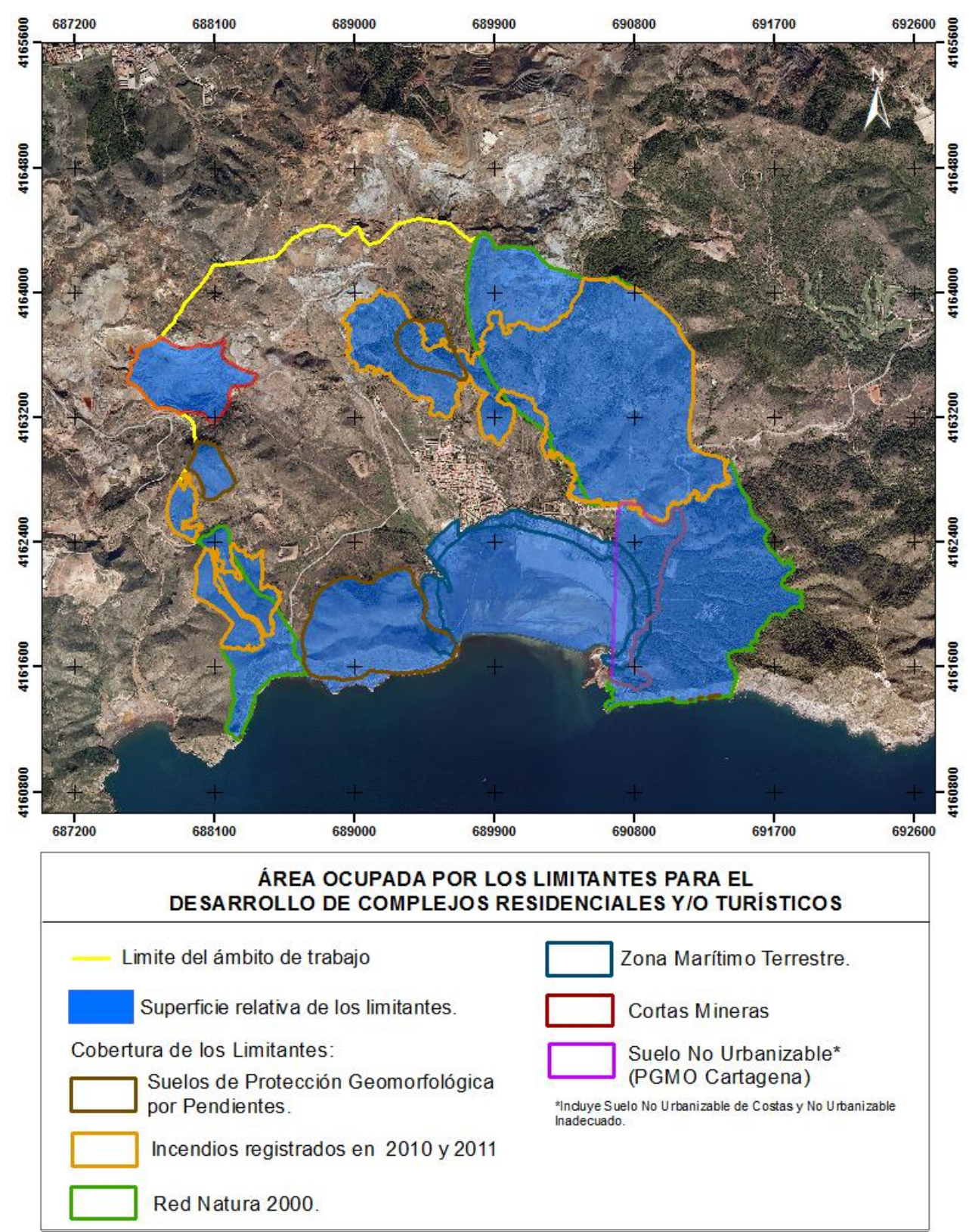

Fuente: Elaboración propia.

- Suelos de protección geomorfológica por pendientes $(67,60 \mathrm{Ha}$.), establecidos por las DPOTL, ya que constituyen terrenos con condiciones constructivas muy desfavorables.

- El ámbito de los incendios de 2010 y 2011 (208 Ha.), en su mayoría coincidentes con el espacio LIC en la parte de Peña del Águila. La Ley 43/2003 de Montes prohíbe el cambio de uso forestal al menos durante 30 años. En el caso del

Revista de Estudios Andaluces, vol. 34, núm. 1 (2017) pp. 89-119. e-ISSN: 2340-2776

http://dx.doi.org/10.12795/rea.2017.i34.04

\section{(c) (i) $(9)$}

SinObraDerivada 4.0 Internacional 
Ayuntamiento de La Unión, como se ha indicado, no puede acogerse a las excepciones que la Ley 21/2015 contempla; por tanto, en estas áreas incendiadas no podrán desarrollarse planeamientos urbanísticos en dicho período.

- Área oriental de la bahía (30 Ha.), limítrofe al límite del LIC de Calblanque, Monte de las Cenizas y Peña del Águila, correspondiente al Término Municipal de Cartagena, ya que la clasificación de este suelo en el Plan General Municipal de Ordenación es la de suelo No Urbanizable.

- El ámbito de la Red Natura 2000 (337,65 Ha.). En el caso del LIC Calblanque, Monte de las Cenizas y Peña del Águila, existe un área urbanizable, recogida en el Plan de Ordenación de los Recursos Naturales (PORN) aprobado en 1995, que permite en esta zona cierto desarrollo turístico. Dadas las declaraciones públicas desde el Ayuntamiento de Cartagena y la Comunidad Autónoma al respecto, en las que se manifiesta una clara intención de no urbanizar esta zona y que se confirman con la clasificación de suelo no urbanizable comentada en el párrafo anterior, se recoge todo el LIC como limitante para el desarrollo de complejos urbanísticos o residenciales.

- En el caso de la ZEPA y LIC Sierra de La Fausilla, no existe aprobación del PORN ni del Plan de Gestión, pero por coherencia con los criterios del LIC anterior, con la perspectiva de conservación de los espacios de la Red Natura 2000 y junto con la topografía abrupta característica, estos espacios también se integran como áreas sin aprovechamiento urbanístico.

- Corta de San José (27 Ha.). El proyecto de regeneración y adecuación ambiental de la bahía de Portmán, actualmente en fase de ejecución, prevé el relleno de esta corta por los residuos mineros dragados. Posteriormente se procederá a su sellado, sobre el que podría desarrollarse un plan de regeneración de la cubierta vegetal. Sin embargo, no parece posible plantearse construcciones que impliquen cimentación sobre esta estructura. Por ello también se considera limitante para complejos residenciales o turísticos.

\subsubsection{CONDICIONANTES PRINCIPALES}

Estas zonas, cuyo desarrollo está fuertemente supeditado a la eliminación previa del riesgo minero y la contaminación del suelo, así como para el mantenimiento de los valores naturales del entorno, ocupan una superficie de 698,40 Ha., lo que representa un $74,56 \%$ del total del ámbito de estudio. Las áreas con estos condicionantes (Figura 7) corresponden a:

- Suelo Protegido por Riesgo Minero (581,41 Ha.). Recogido en las Directrices y Plan de Ordenación Territorial del Litoral, ocupa el 43\% del ámbito de estudio, equivale a la zona de mayor intensidad de las explotaciones mineras en la Sierra. El desarrollo de cualquier actividad, incluida la urbanística, está condicionado a

Revista de Estudios Andaluces, vol. 34, núm. 1 (2017) pp. 89-119. e-ISSN: 2340-2776 http://dx.doi.org/10.12795/rea.2017.i34.04 


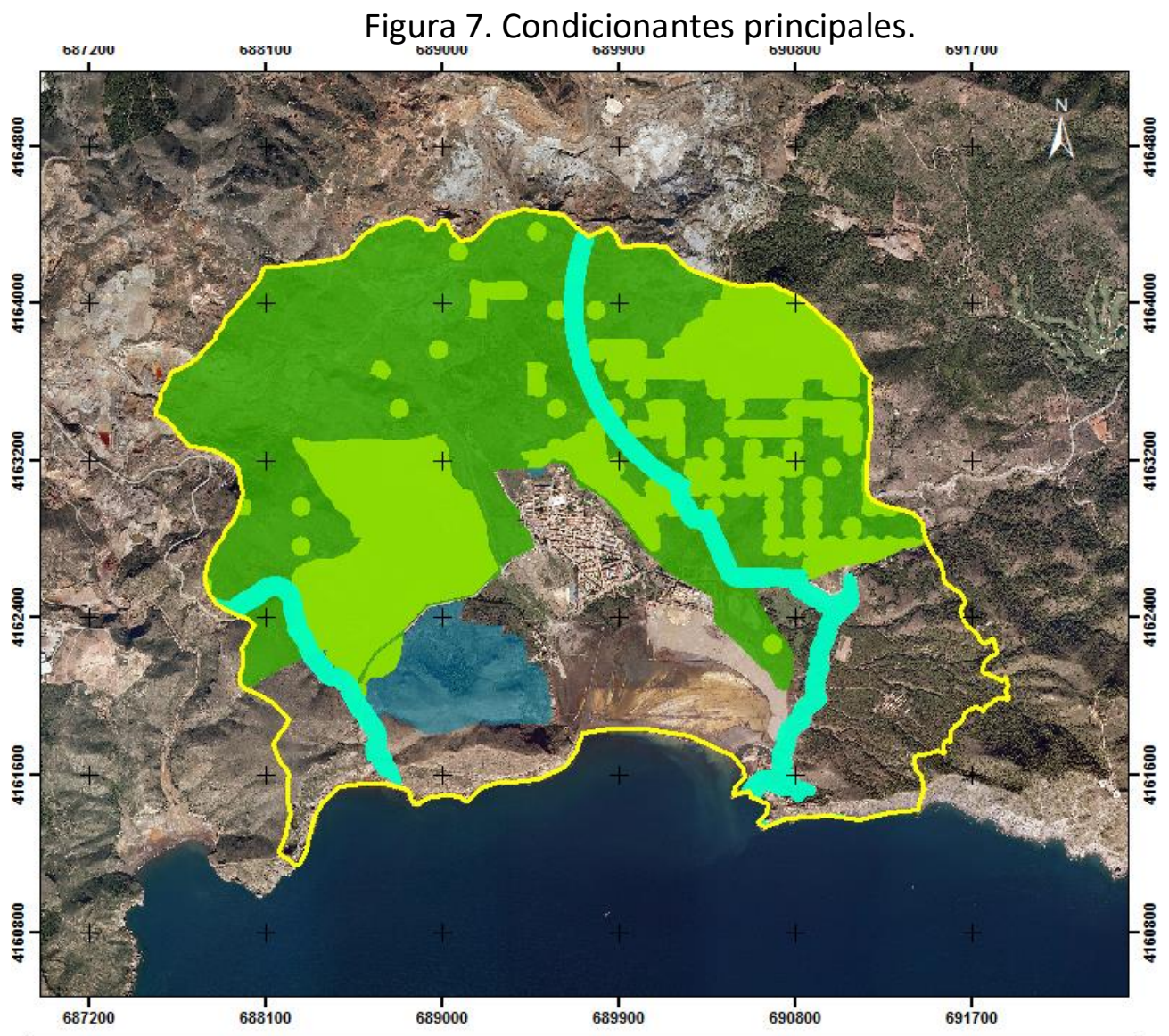

\begin{tabular}{|l|}
\hline \multicolumn{1}{|c|}{ CONDICIONANTES PRINCIPALES } \\
\hline$\square$
\end{tabular}

Fuente: Elaboración propia.

la previa eliminación del riesgo. En ella deberían incluirse tanto los impactos directos como los difusos, por lixiviación o erosión eólica, ya que implican la presencia de elevadas concentraciones de metales pesados con alto poder corrosivo en puntos alejados de su lugar de depósito, que pueden comprometer la estabilidad de las estructuras construidas. Toda esta área se debe considerar también como "suelo potencialmente contaminado", por lo que la recuperación ambiental es obligatoria para los propietarios del terreno o promotores de las actuaciones (Real Decreto 9/2005). De esta forma, dado el conjunto de riesgos,

Revista de Estudios Andaluces, vol. 34, núm. 1 (2017) pp. 89-119. e-ISSN: 2340-2776

http://dx.doi.org/10.12795/rea.2017.i34.04

\section{(c) (i) (9)}

SinObraDerivada 4.0 Internacional 
su extensión y coste de recuperación ambiental, actúan como un condicionante muy substancial para el aprovechamiento urbanístico del ámbito de estudio. Además del suelo protegido por riesgos de la minería establecido por las DPOTL, se ha considerado la superficie de minados, dado que éstos también condicionan la estabilidad de las construcciones. Ambas superficies son coincidentes casi en su totalidad, aunque los puntos de minados quedan más próximo al núcleo de población de Portmán.

- Áreas con hábitats prioritarios y muy raros 5220 y 9570 (273 Ha.). Los Criterios Orientadores del Medio Natural de 2008 (y también en su versión de 2012), recogen "la desaparición de una hectárea de hábitats prioritarios o raros o muy raros como impacto ambiental crítico inasumible". Además, consideran que las áreas no incluidas en espacios protegidos con valores naturales, como hábitats prioritarios o poblaciones reconocibles de especies protegidas, deberían ser clasificadas como Suelo No Urbanizable por el Planeamiento. Basado en estos Criterios, se ha optado por una perspectiva conservadora, seleccionando, exclusivamente, áreas que cumplen ambas exigencias; es decir, que tengan hábitats muy raros y prioritarios cuyas especies directrices formen parte de poblaciones de especies protegidas. Esta particularidad la cumplen los hábitats 9570 y 5220.

En el caso del Tetraclinis articulata (9570), cabe recordar que esta especie está incluida en el Listado de Especies Silvestres en Régimen de Protección Especial y en el Catálogo Español de Especies Amenazadas y, por tanto, prohibida su destrucción intencionada en la naturaleza (Ley 42/2007).

Se ha calculado una superficie bruta de unas $273 \mathrm{Ha}$. con presencia de alguno de estos hábitats. No obstante, esta extensión podría ser mayor si además se incluyen otras zonas de cornical (Periploca angustifolia y Maytenus senegalensis subsp. europaea) y el resto de hábitats raros o prioritarios $(1240,6220$, muy extendido, y 8210). Por otra parte, es preciso destacar que de estas $273 \mathrm{Ha}$., el $78 \%$ se extiende sobre suelos con riesgo minero y potencialmente contaminados. Cerca del núcleo de Portmán se detectan áreas en las que ambos condicionantes (riesgo minero y suelo potencialmente contaminado y hábitats prioritarios y muy raros) coinciden, lo que condiciona, en gran medida, el aprovechamiento urbanístico.

- Zona de amortiguación de los espacios de la Red Natura 2000 (56,83 Ha.). Se corresponde con una banda perimetral mínima de 100 metros establecida en los Criterios Técnicos Orientadores del Medio Natural. El aprovechamiento urbanístico que se puede desarrollar en esta banda se limita a zonas verdes de protección y equipamientos deportivos descubiertos, sin comprometer los valores naturales asociados a estos espacios.

Revista de Estudios Andaluces, vol. 34, núm. 1 (2017) pp. 89-119. e-ISSN: 2340-2776 http://dx.doi.org/10.12795/rea.2017.i34.04 


\subsubsection{CONDICIONANTES ADICIONALES}

Los condicionantes adicionales (Figura 8) ocupan todo el ámbito de estudio menos el núcleo de Portmán y su entorno más inmediato. Se corresponde con unas $882,40 \mathrm{Ha}$., el $94.20 \%$. Por tanto, dentro de estos condicionantes quedan incluidos:

- Condicionantes adicionales del Medio Natural:

- Corredor Ecológico número 47 de la Red de Corredores de la Región de Murcia $(445,26 \mathrm{Ha}$.), que engloba La Galera y toda la porción noroeste del ámbito de estudio.

- Área Prioritaria para las Aves $(477,51 \mathrm{Ha}$.), a efectos de la adopción de medidas protectoras en líneas eléctricas aéreas, que se extiende por La Galera, la bahía y todo el extremo oriental del territorio analizado, coincidente con el LIC de Calblanque, Monte de las Cenizas y Peña del Águila.

- Zona de influencia de la Red Natura 2000 (de 371,14 Ha.), que conforma una banda perimetral de $1000 \mathrm{~m}$.

- Micro-reservas de flora, que en el ámbito de estudio se encuentran en la zona Sur de La Galera con 26,58 Ha. y otra, en las inmediaciones de la Peña del Águila, con una superficie no superior a las $5 \mathrm{Ha}$.

- Suelo de Protección Ambiental (302,42 Ha.), coincide con la superficie donde se integran los espacios de la Red Natura 2000 del ámbito de estudio.

- Condicionantes adicionales del Patrimonio Cultural:

- Yacimientos concentrados en la zona norte de Portmán, y el área Oeste en el entorno del Monte del Pino y la Cantera San José-Gloria Este.

- Bienes de Interés Cultural, como los ya mencionados Huerta del Paturro y las Balsas Romanas como BIC declarado, así como de los edificios del Tío Lobo y el Hospital de la Caridad, ubicados en el centro urbano. En cuanto al BIC propuesto del Paisaje Minero, presenta una gran extensión en el ámbito de estudio, englobando gran parte de los yacimientos.

- Lugar de Interés Geológico de la Sierra Minera, que se extiende ocupando la totalidad del ámbito de estudio.

- Condicionantes adicionales ligados a régimen de protección del suelo (Directrices y Plan de Ordenación Territorial del Litoral):

- Suelo de protección por cauces, asociado al riesgo de inundación de las ramblas Del Infierno y La Boltada y los barrancos Del Moro y La Culebra. Esta protección tiene carácter preventivo y sus límites pueden ser modificados a partir de un estudio hidrológico.

- Suelo afecto a la defensa y protección nacional, en el que es posible el desarrollo turístico, previo acuerdo de las administraciones competentes. 
Figura 8. Condicionantes adicionales para el desarrollo urbanístico.

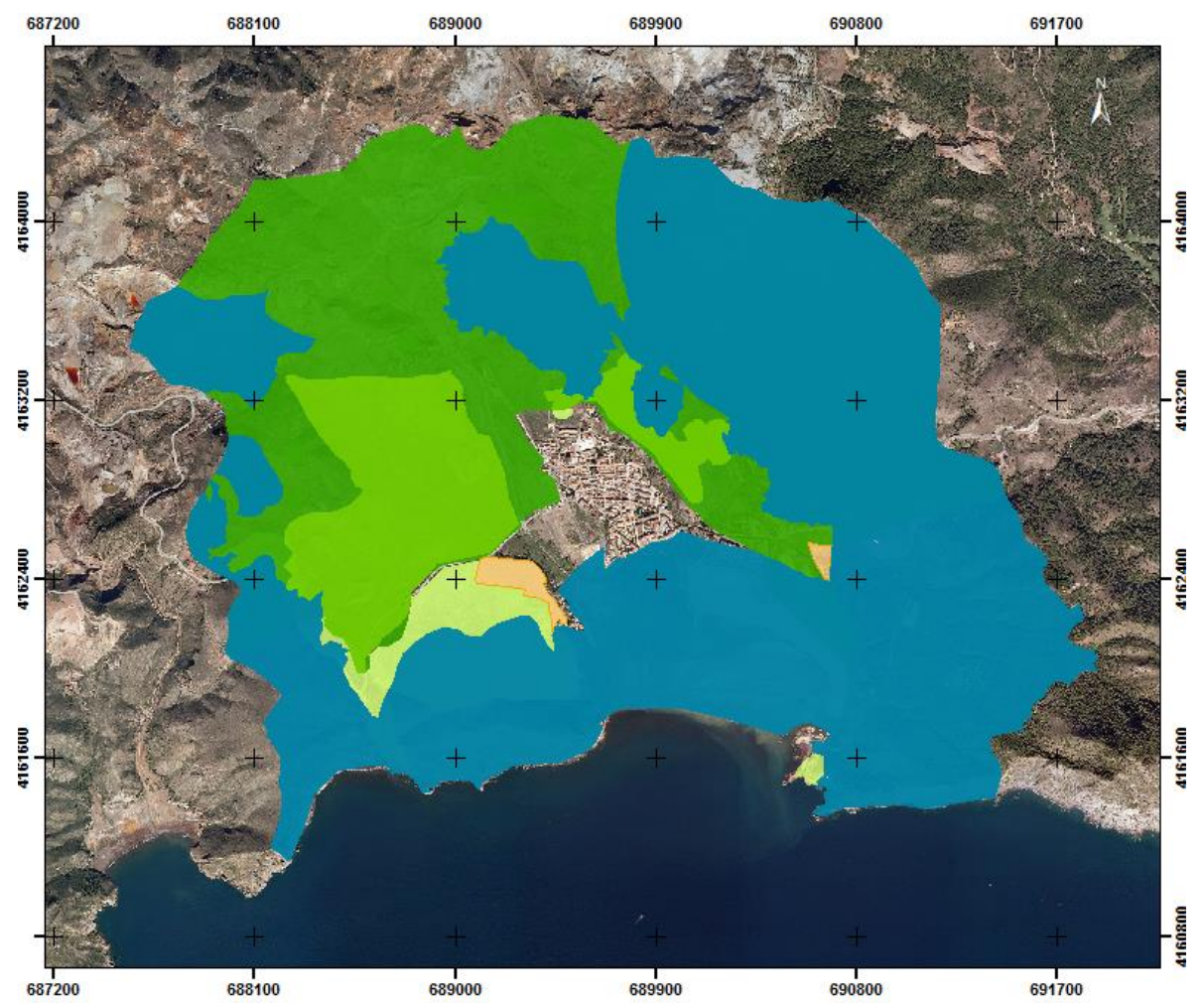

\begin{tabular}{|c|c|}
\hline \multicolumn{2}{|c|}{$\begin{array}{l}\text { APTITUDES DE USO DEL TERRITORIO PARA EL DESARROLLO DE } \\
\text { COMPLEJOS RESIDENCIALES YIO TURISTICOS. }\end{array}$} \\
\hline Ámbito de trabajo & Áreas condicionadas: \\
\hline Área incompatible. & Por valores ligados al Patrimonio Natural \\
\hline $\begin{array}{l}\text { Áreas fuertemente condicionadas: } \\
\text { Por riesgo minero y suelo } \\
\text { potencialmente contaminado con } \\
\text { fragmentos dispersos de hábitats } \\
\text { prioritarios y muy raros }\end{array}$ & * Complejos residenciales y/o turísticos. \\
\hline $\begin{array}{l}\text { Por riesgo minero y suelo } \\
\text { potencialmente contaminado y hábitats } \\
\text { prioritarios y muy raros }\end{array}$ & \\
\hline $\begin{array}{l}\text { Por hábitats prioritarios y muy raros y } \\
\text { banda de amortiguación RNO0 }(100 \mathrm{~m})\end{array}$ & \\
\hline
\end{tabular}

Fuente: Elaboración propia.

\section{APTITUDES DEL USO DEL TERRITORIO}

El análisis conjunto de los limitantes, los condicionantes principales y los condicionantes adicionales identificados, permite una visión global y un análisis integrado de las aptitudes del uso del ámbito estudiado. La integración de todas las categorías implica la ocupación de 895,91 Ha. Es decir, que el 95,64\% del territorio presenta algún elemento de interés ambiental, natural, cultural o riesgo; o bien alguna figura de protección o de

Revista de Estudios Andaluces, vol. 34, núm. 1 (2017) pp. 89-119. e-ISSN: 2340-2776 http://dx.doi.org/10.12795/rea.2017.i34.04 (c) (i) (8) 
ordenación, a la que se subordina o, en todo caso, condiciona, el aprovechamiento residencial o turístico (Tabla 4).

Bajo estos criterios de jerarquía espacial, casi un 60,5\% del territorio presenta algún elemento limitante y por tanto incompatible, con el desarrollo urbanístico, lo que supone casi dos tercios del ámbito de estudio. Esta área se extiende por todo el extremo Sur y Este del territorio analizado; mientras que en la zona Oeste la extensión de superficie con categoría limitante, es menor y se encuentra ligada con el límite del ámbito.

Los condicionantes principales ocupan la zona centro y noroccidental, coincidiendo con el área de mayor intensificación de uso minero. De esta forma, el riesgo ligado a la minería y los suelos potencialmente contaminados se localiza a modo de mancha continúa, con una superficie total adicional de 205,85 ha, no coincidentes con las áreas de limitantes. En estas zonas, el desarrollo urbanístico está fuertemente condicionado, no sólo por la imposición legal de previa eliminación del riesgo y de descontaminación de los suelos, sino también por la propia fragilidad del terreno, que limita severamente la viabilidad económica de su edificación.

Junto a los condicionantes ligados a la explotación minera, en la zona Oeste inmediata al entorno urbano de Portmán y la planicie que la conecta con el Monte del Pino y del Laberinto, destaca la presencia de hábitats prioritarios y muy raros (5220 y 9570), con especies vulnerables como Maytenus senegalensis subsp. europaea, Periploca angustifolia y Tetraclinis articulata, además de especies de interés especial como Rhamnus alaternus, Chamaerops humilis y Osyris lanceolata, que suelen estar asociadas a las anteriores, conformando comunidades vegetales de elevado valor de conservación.

En estas zonas también existen riesgos de la minería, asociados principalmente a los minados $y$, por tanto, con presencia de suelos potencialmente contaminados. Sin embargo, en las zonas en las que la intensificación minera ha sido menor, se han desarrollado estas comunidades vegetales de gran interés tanto en el contexto regional como europeo. De ahí las estrategias de protección mencionadas que a ellas se vinculan. Todas las áreas con riesgo minero y suelo potencialmente contaminado en las que se desarrollan hábitats muy raros y prioritarios, suponen $96,94 \mathrm{Ha}$. del territorio no ocupado por factores limitantes.

Otro de los espacios donde no existen estos factores limitantes, es el caso de la cara Norte de La Galera, donde se observan extensiones de hábitats prioritarios y muy raros con el código 5220 y 9570 . En esta zona, cuya superficie es de 18,48 Ha. no existe riesgo minero, por lo que el aprovechamiento urbanístico se supedita en exclusiva a condicionantes principales ligados a estos importantes valores naturales. La pendiente

Revista de Estudios Andaluces, vol. 34, núm. 1 (2017) pp. 89-119. e-ISSN: 2340-2776 http://dx.doi.org/10.12795/rea.2017.i34.04 
Tabla 4. Análisis de los limitantes y condicionantes territoriales. Superficies expresadas en hectáreas.

\begin{tabular}{|l|l|}
\hline $\begin{array}{l}\text { LIMITACIONES Y CONDICIONANTES TERRITORIALES } \\
\text { PARA EL DESARROLLO URBANíSTICO }\end{array}$ & $\begin{array}{l}\text { SUPERFICIE NETA } \\
\text { (Ha) }\end{array}$ \\
\hline Áreas incompatibles & 566,33 \\
\hline Áreas fuertemente condicionadas & 322,84 \\
\hline Áreas condicionadas & 6,74 \\
\hline Superficie total neta & 895,91 \\
\hline \% total neto & $95,64 \%$ \\
\hline
\end{tabular}

Fuente: Elaboración propia.

del terreno y su cuenca visual a espaldas del mar, podría limitar, en principio, el interés para el aprovechamiento residencial en esta zona.

Considerando los condicionantes adicionales para el espacio restante, destaca principalmente la presencia de dos yacimientos arqueológicos calificados con el grado A: yacimiento de La Galera, y una parte de Huerta del Paturro. Estas zonas, además, presentan valores naturales, pues están incluidas dentro del área prioritaria para las aves y la zona de influencia de la Red Natura 2000. El cabezo de La Galera, además, se incluye en el corredor ecológico 47. De esta forma, con una superficie total de 5,69 Ha. estas zonas se encuentran ligadas a condicionantes del medio natural y del patrimonio arqueológico.

La localización de Portmán fortalece la propuesta de revalorización de su riqueza natural e histórica, en la que la vertiente Sur del Mar Menor y La Manga ofrecen un turismo convencional basado en la concentración de conjuntos residenciales. Sin embargo, las singularidades mineras y pesqueras unidas a los valores naturales del entorno de Portmán permiten una oferta complementaria y escasa en el contexto regional, basada en el turismo de raíz cultural. El potencial turístico de esta oferta ya es patente en los más de 25.000 visitantes que en 2010 recibió el Paisaje Minero de La Unión y Cartagena, lo cual justifica la integración de Portmán, para conformar un Gran Parque Minero Regional, orientado a un crecimiento socioeconómico de calidad, que implique al tejido social de este entorno en su diseño y desarrollo.

\section{CONCLUSIONES}

De los resultados de este análisis se desprende que la superficie neta de limitantes y de condicionantes principales, como categorías territoriales principales, representa el 94,63\% del territorio analizado. Llegando a alcanzar un 95,64\% al sumar al análisis los condicionantes adicionales. Esto pone de manifiesto la complejidad y la existencia de serias limitaciones para el aprovechamiento urbanístico del entorno de Portmán, debido a la configuración existente en la actualidad como resultado de su historia minera y los valores ambientales singulares que presenta.

Revista de Estudios Andaluces, vol. 34, núm. 1 (2017) pp. 89-119. e-ISSN: 2340-2776 http://dx.doi.org/10.12795/rea.2017.i34.04

\section{c) (i) $\$(9)$}


La integración espacial de limitantes, condicionantes principales y condicionantes adicionales aplicada en este caso de estudio, ha demostrado ser una herramienta adecuada para cualquier proceso de ordenación del territorio y la toma de decisiones, y que podría de ser incorporada a otros estudios de planificación de los usos del territorio. A la vista de los resultados, el desarrollo de Portmán debería orientarse preferentemente hacia la puesta en valor de su identidad ambiental, minera y pesquera, más que a través de un proceso de transformación hacia un uso turístico convencional. A este respecto, como una evidencia más de los valores de este entono, en 2005 se inició la propuesta como Reserva de la Biosfera al conjunto de Calblanque, Peña del Águila y Monte de las Cenizas, que posteriormente también incluyó áreas del entorno, englobando la bahía de Portmán. La declaración como Reserva de la Biosfera, en la que aún hoy se sigue trabajando desde algunos grupos sociales, supondría un valor añadido en esta zona y actuaría como foco de atracción para el turismo.

\section{AGRADECIMIENTOS}

A la Dirección General de Sostenibilidad de la Costa y del Mar que ha financiado el trabajo "Análisis y definición conceptual previa de la integración ambiental entre la recuperación de la bahía de Portmán y la Sierra Minera (criterios y actuaciones de conexión e integración entre la restauración de la bahía de Portmán y la conservación y regeneración de la Sierra Minera y su biodiversidad como medio para un desarrollo local sostenible)". Las opiniones expresadas en este trabajo son exclusiva responsabilidad de los autores, no constituyendo la posición oficial de la citada Dirección General.

\section{REFERENCIAS}

Banos-González y Baños Páez (Eds) (2013). Portmán: de el Portus Magnus del Mediterráneo Occidental a la Bahía Aterrada. EDITUM.

Baraza (ed.) (1999). Los hábitats comunitarios en la Región de Murcia. Consejería de Agricultura, Agua y Medio Ambiente. Comunidad Autónoma de la Región de Murcia.

Belmonte Serrato, F.; Romero Díaz, A. y Moreno Brotóns, J. (2010). Contaminación ambiental por estériles mineros en un espacio turístico en desarrollo, la Sierra Minera de Cartagena-La Unión (Sureste de España). Cuadernos de turismo, 25, 11-24.

Benedicto, J., Martínez-Gómez, C., Guerrero, J., Jornet, A., \& Rodriguez, C. (2008). Metal contamination in Portman Bay (Murcia, SE Spain) 15 years after the cessation of mining activities. Contaminación por metales en la bahía de Portmán (Murcia, SE España) 15 años después del cese de las actividades mineras. Ciencias Marinas, 34, 389-398.

Revista de Estudios Andaluces, vol. 34, núm. 1 (2017) pp. 89-119. e-ISSN: 2340-2776 http://dx.doi.org/10.12795/rea.2017.i34.04

\section{(c) (i) (3)}

SinObraDerivada 4.0 Internacional 
Benedicto, J., Martínez-Gómez, C., Ruiz-Fernández, J. M. (2013). La Calidad del Medio Marino en Portmán y su entorno: Evolución y Estado Actual de Conocimiento. En: BanosGonzález y Baños Páez (Eds). Portmán: de el Portus Magnus del Mediterráneo Occidental a la Bahía Aterrada. EDITUM, pp: 345-392.

Benseny, G. (2006). El espacio turístico litoral. Aportes y Transferencias, 10, 102-122.

BOE (Boletín Oficial del Estado) (2011). Proyecto de regeneración y adecuación ambiental de la bahía de Portmán; t.m. La Unión (Murcia) (BOE no 228, de 22/09/2011), 87768-87769.

BORM (Boletín Oficial de la Región de Murcia) (2004). Decreto no 57/2004, de 18 de junio, por el que se aprueban las «Directrices y Plan de Ordenación Territorial del Litoral de la Región de Murcia». (BORM no 145, de 25/06/2004), 14167- 14222

BORM (Boletín Oficial de la Región de Murcia) (2012): Orden 11714 del Excmo. Sr. Consejero de Obras Públicas y Ordenación del Territorio, de fecha 17 de julio de 2012, relativa a toma de conocimiento del Texto Refundido de la Revisión del P.G.M.O. de Cartagena. (BORM № 173, de 27/07/2012), 32344- 32597.

Díez Rubio, G. y González Ortega, J. M. (2011). Proyecto de Regeneración y Adecuación Ambiental de la Bahía de Portmán. T.M. de La Unión, Murcia.

Espinosa, J.A. y Rodríguez, F. (2015). Tendencias y oportunidades de desarrollo turístico en la Costa Tropical de Granada: la visión de los municipios. Cuadernos de turismo, 35, 133-156.

Esteve Selma, M. A.; Miñano Martínez, J.; Carrión Vilches, M.A. y Aledo Olivares, E. (2010). Plan de Conservación de Tetraclinis articulata en la Región de Murcia. Dirección General de Patrimonio Natural y Biodiversidad, Consejería de Agricultura y Agua, Comunidad Autónoma de la Región de Murcia

García, C.; Manteca, J.I. y Rodríguez, T. (2001). Inventario de pozos mineros de la Región de Murcia (Sierra de Cartagena). Consejería de Tecnología, Industria y Comercio de la Comunidad Autónoma de la Región de Murcia.

García, C. (2004). Impacto y riesgo ambiental de los residuos minero-metalúrgicos de la Sierra de Cartagena-La Unión (Murcia-España). Tesis Doctoral. Universidad Politécnica de Cartagena. Departamento de Ingeniería Minera, Geológica y Cartográfica.

López, J.; Calvo J.; Esteve Selma, M. y Ramírez Diaz, L. (1995). Respuesta de Tetraclinis articulata (Vahl) Masters al fuego. Ecología 9, 213-221. 
Manteca, I. (2013). Introducción a la geología y yacimientos minerales de Portmán. En: Banos-González y Baños Páez (Eds), Portmán: Del Portus Magnus del Mediterráneo Occidental a la Bahía Aterrada. EDITUM, pp: 51-91.

Manteca, I.; Ovejero, G. (1992). Los yacimientos Pb, Zn, Ag-Fe del distrito minero de la Unión-Cartagena, Bética Oriental. En: García-Guinea J, Martínez-Frías J (eds.), Recursos Minerales de España. CSIC, pp: 1085-1102.

Martínez, E. y Calvo, J.F. (2006). Rapaces diurnas y nocturnas de la Región de Murcia. Consejería de Industria y Medio Ambiente. Región de Murcia.

Real Decreto 9/2005, de 14 de enero por el que se establece la relación de actividades potencialmente contaminantes del suelo y los criterios y estándares para la declaración de suelos contaminados. (BOE no 15, de 18/01/2005), 1833- 1843.

Ley 42/2007, de 13 de diciembre, de Patrimonio Natural y de la Biodiversidad (BOE no 299, de 14/12/2007), 51275-51327. Decreto 50/2003 de 30 de mayo, por el que se crea el Catálogo Regional de Flora Silvestre Protegida de la Región de Murcia y se dictan normas para el aprovechamiento de diversas especies forestales (BORM no 131, de 10/06/2003), 11615-11624.

López Bermúdez, F. (2013). Prólogo. En: Banos-González y Baños-Páez (Eds), Portmán: de El Portus Magnus del Mediterráneo Occidental a la Bahía Aterrada, pp. 13-19. EDITUM.

Vera Rebollo, F., López Palomeque, F., Marchena Gómez, M. y Antón Clave, S. (1997). Análisis territorial del turismo. Una nueva geografía del turismo. Barcelona, Editorial Ariel.

Revista de Estudios Andaluces, vol. 34, núm. 1 (2017) pp. 89-119. e-ISSN: 2340-2776 http://dx.doi.org/10.12795/rea.2017.i34.04

\section{(c) (i) ()}

